\title{
Patterns of within-stem variations in wood specific gravity and water content for five temperate tree species
}

\author{
Fleur Longuetaud ${ }^{1,2} \cdot$ Frédéric Mothe $^{1,2} \cdot$ Philippe Santenoise $^{1,3} \cdot$ Ndiaye Diop $^{4}$. \\ Jana Dlouha $^{1,2}$ - Meriem Fournier ${ }^{1,2}$ - Christine Deleuze ${ }^{5}$
}

Received: 15 November 2016 / Accepted: 18 July 2017 / Published online: 7 September 2017

(C) INRA and Springer-Verlag France SAS 2017

\begin{abstract}
- Key message Intensive measurements of basic specific gravity and relative water content of lumens show that within-stem variations strongly depend on species and cannot be summarised through the typical patterns
\end{abstract}

\footnotetext{
Handling Editor: Jean-Michel Leban

Contribution of the co-authors Fleur Longuetaud: designed the experiment, run the data analysis and was the main writer.

Frédéric Mothe: designed the experiment, run the data analysis and contributed to the writing.

Philippe Santenoise: helped to run the data analysis and contributed to the writing.

Ndiaye Diop: helped to run the data analysis and contributed to the writing.

Jana Dlouha: helped with discussions and contributed to the writing. Meriem Fournier: helped with discussions and contributed to the writing.

Christine Deleuze: supervised the work and coordinated EMERGE project.
}

This article is part of the Topical Collection on Estimation of standing forest biomass.

Fleur Longuetaud

fleur.longuetaud@inra.fr

Frédéric Mothe

frederic.mothe@inra.fr

Philippe Santenoise

philippe.santenoise@inra.fr

Ndiaye Diop

ndiaye.diop@ucad.edu.sn

Jana Dlouha

jana.dlouha@inra.fr

Meriem Fournier

meriem.fournier@agroparistech.fr

Christine Deleuze

christine.deleuze@onf.fr reported in the literature; breast height measurements are not always representative of the whole stem.

- Context Knowledge of the distribution of wood properties within the tree is essential for understanding tree physiology as well as for biomass estimations and for assessing the quality of wood products.

- Aims The radial and vertical variations of basic specific gravity (BSG) and relative water content of lumens $\left(\mathrm{RWC}_{L}\right)$ were studied for five species: Quercus petraea/robur, Fagus sylvatica, Acer pseudoplatanus, Abies alba and Pseudotsuga menziesii. The observations were compared with typical patterns of variations reported in the literature.

- Methods Wood discs were sampled regularly along tree stems and X-rayed in their fresh and oven-dry states.

- Results At breast height, BSG was found to clearly increase radially (pith to bark) for two species and to decrease for one species. For F. sylvatica and A. alba, the radial variations of BSG were rather U-shaped, with in particular inner wood areas showing respectively lower and higher BSG than the corresponding mature wood. $\mathrm{RWC}_{L}$

1 INRA, UMR1092 LERFoB, 54280 Champenoux, France

2 AgroParisTech, UMR1092 LERFoB, 54000 Nancy, France

3 INRA, Unité Biogéochimie des Ecosystèmes Forestiers, 54280 Champenoux, France

4 Ecole Supérieure Polytechnique, Université Cheikh Anta Diop de Dakar (UCAD), Corniche Ouest BP, 5085 Dakar-Fann, Sénégal

5 ONF, Département R\&D, 39100 Dole, France 
increased generally from inner to outer area but wet sapwood was clearly distinguishable only for the coniferous species. Vertical variations of BSG and $\mathrm{RWC}_{L}$ were strongly dependant on the species with usually non-linear patterns.

- Conclusion The observed variations of BSG were only partially in agreement with the reported typical radial patterns. Despite the vertical variations, the mean BSG of a cross-section at breast height appeared to be a good estimator of the mean BSG of the whole stem (although the difference was statistically significant for coniferous species), whereas breast height measurement of $\mathrm{RWC}_{L}$ was not representative of the whole stem.

Keywords Basic density - Relative water content - Degree of lumen saturation $\cdot$ Sapwood $\cdot$ Radial and vertical variations

\section{Introduction}

Ontogeny and environmental growth conditions are the main sources of heterogeneity of wood properties within stems and between trees of the same species. Moreover, different species have different ecological strategies related to their anatomical structure, architectural characteristics and environment. For instance, successional status and shadetolerance are species-specific characteristics that are known to affect the patterns of within-stem variations of wood specific gravity (Woodcock and Shier 2002).

Most of the time the variations of wood properties are studied at breast height from increment cores, mainly for practical reasons. By means of a more intensive sampling along the stem and by using X-ray computed tomography for analysing the sample discs, it is possible to access relatively easily radial, azimuthal and vertical variations within stem of some wood properties related to wood specific gravity and/or water content (Longuetaud et al. 2016). (Longuetaud et al. 2016) showed that among the studied variables, two were statistically independent and thus were suitable to be used as complementary traits for characterising species: basic specific gravity (BSG), which is the ratio of oven-dry weight to green volume relative to the density of water, and relative water content of lumens $\left(\mathrm{RWC}_{L}\right)$, which is the proportion of the cell voids occupied by water.

BSG is a property inherent to the wood material, whereas $\mathrm{RWC}_{L}$ varies with time and is particularly interesting when it is studied in the living tree. BSG is a key variable that is used as an indicator of wood quality and for biomass estimations. BSG is related to some mechanical and hydraulic functions (Hacke et al. 2001; Chave et al. 2009) while some other mechanical (Larjavaara and Muller-Landau 2010) and hydraulic (Zanne et al. 2010) functions do not depend on wood density. $\mathrm{RWC}_{L}$ is mainly related to hydraulic functioning of the tree because it describes the amount of stored water potentially available to buffer the fluctuations of water potential in the tissue and it is thus related to the capacitance function of the tree. However, $\mathrm{RWC}_{L}$ does not provide information about the actual accessibility of this water for the tree nor the kinetics of its withdrawal as a function of the change in water potential. It gives a fixed information about the volume of water stored in the cell voids including vessel or tracheid lumens, parenchyma cells, fibre lumens and intercellular spaces.

Radial variations of wood properties (among others: cell size, specific gravity, microfibril angle, modulus of elasticity, spiral grain angle, specific conductivity) have been widely studied (e.g. Zobel and Sprague 1998; Woodcock and Shier 2002; Lachenbruch et al. 2011; Plourde et al. 2015) and typical radial patterns (TRP) of variations of functional or material properties of wood have been reported (Lachenbruch et al. 2011). However, some radial trends may be strongly modified by changing growth conditions for the same species (McLean et al. 2011).

In tropical forests, radial variations of BSG are often assumed to be related to an inter-specific trade-off between growth and risk of damage or death of the trees (King et al. 2006; Osazuwa-Peters et al. 2014). Trying to analyse the functional relevance of observed radial patterns beyond the mean values of both tropical and temperate tree species, Woodcock and Shier (2002) proposed a model in which "radial increases [of $S G$ ] associated with low values of [initial] specific gravity are an early-successional characteristic and radial decreases [of $S G$ ] associated with high values of [initial] specific gravity late successional". Similar observations were made in other studies on tropical tree species (Osunkoya et al. 2007; Schüller et al. 2013; Hietz et al. 2013; Plourde et al. 2015; Bastin et al. 2015). The relatively high number of recent studies is due to the importance of studying BSG variations for biomass estimations. Early-successional species grow faster at the beginning of their life with a wood of low specific gravity and later they tend to produce denser wood. These species are generally known to be less resistant to attacks by pests and pathogens and to damage caused by their direct environment (e.g. falling woody materials) and have also higher mortality rate than species having high specific gravity wood (King et al. 2006; Osunkoya et al. 2007; Chave et al. 2009). For temperate tree species, the relationship between BSG radial pattern and shade-tolerance or species successional status is not always clear (Wiemann and Williamson 1989), but this relationship has been much less studied than for tropical species. 
In comparison with specific gravity, the radial variations of wood water content have been even less studied. The differences in water content of heartwood and sapwood have been analysed on several species by Fromm et al. (2001) and Gartner et al. (2004), showing generally larger differences in softwood species than in hardwood species. The hydraulic conductivity of the xylem has been analysed in several studies aiming to determine the depth of conducting sapwood. Gebauer et al. (2008) observed a considerable variation in conductive sapwood depth at breast height among several broadleaved species. The relative water content (RWC) of wood (Domec and Gartner 2002; Bouffier et al. 2003; Meinzer et al. 2003; Scholz et al. 2007), which is the ratio of the amount of water in wood to the maximal amount of water that can be contained in fully saturated wood, has been seldom studied. RWC is in general used to estimate the hydraulic capacitance of wood in order to assess the use of water stored in the tissue. In previous study (Longuetaud et al. 2016), we suggested the use of $\mathrm{RWC}_{L}$ rather than $\mathrm{RWC}$, by removing from the computation of the water available for buffering the fluctuations in water potential the water bound in the cell walls that cannot be withdrawn from the tissue. Use of RWC may indeed introduce an important bias in particular when comparing capacitance of species or wood types (earlywood vs latewood) with contrasted densities.

The vertical variations of wood properties are less studied than the radial variations because data are much more complicated and costly to obtain. According to Zobel et al. (1989), for the species showing a great difference of some wood properties between juvenile and mature wood, it is automatic that a variation with height will be observed for these properties due to the variation with height of the proportion of juvenile wood which increases from the base to the top of the tree. Following the same idea, it is clear that the variations of BSG with height are related to the vertical changes in the proportion of juvenile wood (corewood), growth ring width and cambial age (i.e. some variables known to have an effect on BSG), whereas vertical changes in the proportion of sapwood can probably better explain the water content variations. However, it is important to point out that some variations with height of specific gravity, for example, were also observed within corewood and outerwood when these two stem areas were considered separately (Gilmore and Pearson 1969; Megraw, 1985, in Zobel et al. 1989). It is important to quantify these variations with height in order to assess the representativeness of breast height measurements that are widely used (e.g. Nogueira et al. 2008). This is a key issue considering that the very large majority of wood property measurements are issued from breast height samples, in particular for large scale biomass, carbon stock and carbon flux estimations (Wiemann et al. 2014).

In this work, the within-stem variations of BSG and $\mathrm{RWC}_{L}$ measured by X-ray imaging were studied for three hardwood species (Quercus sp., Fagus sylvatica and Acer pseudoplatanus) and two softwood species (Abies alba and Pseudotsuga menziesii). Three contrasted anatomical patterns (ring-porous, diffuse-porous and softwood) and a wide range of shade-tolerances (Niinemets and Valladares 2006) were represented (Table 1). The methodology based on Xray measurements on discs is detailed in (Longuetaud et al. 2016). The dataset collected for this study concerns more than 1200 discs representing a total of 113 trees. The main questions that were addressed in this work are:

- Are our data in agreement with the theories/ models/patterns of wood density radial variations found in the literature?

- Are breast height measurements representative of the whole stem?

- To what extent are vertical variations of BSG and $\mathrm{RWC}_{L}$ a consequence of radial variations?
Table 1 Characteristics of the species

\begin{tabular}{llr}
\hline Species & $\begin{array}{l}\text { Anatomical } \\
\text { pattern }\end{array}$ & $\begin{array}{l}\text { Shade } \\
\text { tolerance }\end{array}$ \\
\hline Fagus sylvatica & diffuse-porous & $4.56(0.11)$ \\
Acer pseudoplatanus & diffuse-porous & $3.73(0.21)$ \\
Quercus petraea & ring-porous & $2.73(0.27)$ \\
Quercus robur & ring-porous & $2.45(0.28)$ \\
Abies alba & softwood (tracheids) & $4.60(0.06)$ \\
Pseudotsuga menziesii & softwood (tracheids) & $2.78(0.18)$ \\
\hline
\end{tabular}

In our study, Quercus petraea and Quercus robur were not distinguished. Shade-tolerance scores are those provided by Niinemets and Valladares (2006). Standard errors are given in brackets. Tolerance scales range from 0 (no tolerance) to 5 (maximal tolerance) 
Table 2 Characteristics of the sampled trees

\begin{tabular}{lllllll}
\hline Species & Number of trees & Number of discs & Height range $(\mathrm{m})$ & $H F L B^{1}$ range $(\mathrm{m})$ & $D B H^{2}$ range $(\mathrm{cm})$ & Age range $(\mathrm{year})$ \\
\hline Fagus sylvatica & 30 & 255 & $15-28$ & $2-16$ & $11-42$ & $34-76$ \\
Acer pseudoplatanus & 21 & 163 & $16-25$ & $3-12$ & $12-41$ & $28-64$ \\
Quercus petraea/robur & 6 & 73 & $28-32$ & $11-13$ & $30-53$ & $7-32$ \\
Abies alba & 27 & 315 & $9-19$ & $1-9$ & $9-50$ & $36-80$ \\
Pseudotsuga menziesii & 29 & 398 & $10-30$ & $1-19$ & $20-43$ \\
\hline
\end{tabular}

${ }^{1}$ Height of the first living branch

${ }^{2}$ Diameter at breast height

\section{Materials and methods}

\subsection{Experimental material}

The biological material was already used in a previous paper by Longuetaud et al. (2016) which focused on the description of a method for mapping wood properties within-stems by using X-ray computed tomography.

Five temperate species growing in France were sampled: three hardwoods (Quercus petraea/robur, Fagus sylvatica and Acer pseudoplatanus) and two softwoods (A. alba and $P$. menziesii). Quercus species could be either Q. petraea or $Q$. robur since the two species were not differentiated in the field. F. sylvatica and A. pseudoplatanus trees were sampled in February 2009 within an even-aged mixed-stand located in Montiers Forest (48.54 N, 5.30 E). Q. petraea/robur trees were sampled in February 2010 within a pure high-forest located in Amance $(48.76 \mathrm{~N}, 6.33 \mathrm{E})$. A. alba trees were sampled in April 2014 within two even-aged mixed-stands of A. alba and Picea abies located in Mont-Sainte-Marie Forest (46.79 N, 6.31 E) and in Saint-Prix Forest (46.97 N, 4.07 E). Pseudotsuga menziesii trees were sampled in March 2015 within a 20-year-old plantation in Quartier Forest (46.149 N, 2.767 E) and a 43-year-old plantation in Le Grison Forest (46.662 N, 4.736 E). All the trees were sampled in winter or at the beginning of spring and had not started their annual growth when they were harvested.

Three anatomical patterns were represented: softwood pattern with tracheids (A. alba and P. menziesii), diffuseporous pattern ( $F$. sylvatica and A. pseudoplatanus) and ring-porous pattern $(Q$. petraea/robur).
Considering the high correlation existing between shade tolerance and successional status of species, we used the shade tolerance scores provided by Niinemets and Valladares (2006) as a proxy for the successional status of the studied species (Table 1). For instance, F. sylvatica and $A$. alba are shade-tolerant species, although they have very different anatomical structures, and are also well-known to be late-successional species of our European temperate forests. At the opposite, Q. petraea/robur and P. menziesii are rather shade-intolerant, whereas A. pseudoplatanus is intermediate.

Diameter at breast height (DBH), height of the first living branch for hardwood species, height of the first living whorl for softwood species and total tree height were measured.

Wood discs were sampled along stems: every $2 \mathrm{~m}$ from the ground for Q. petraea/robur, F. sylvatica and A. pseudoplatanus; with the distance between discs ranging from 1 to $2 \mathrm{~m}$ for A. alba and P. menziesii. The discs were 5 to $10 \mathrm{~cm}$ thick. A radial saw cut was made on each disc to avoid drying checks. The radial cut was made at the same azimuthal position for all the discs of a given tree.

Table 2 gives the characteristics of the sampled trees. For this study, two A. alba trees (MT3 and MT6 with diameters at breast height of 6.7 and $6.4 \mathrm{~cm}$, respectively) were removed from the sampling since they were too small to allow the data processing described hereafter.

For all species except $Q$. petraea/robur three diameter classes were considered (Table 3). For P. menziesii, the tree diameters were significantly higher in the 43-year-old plantation (mean DBH $=34 \mathrm{~cm}$ ) than in the 20-year-old plantation (mean DBH $=19 \mathrm{~cm}$ ), which means that it was
Table 3 Range of diameters at breast height by size class

\begin{tabular}{llll}
\hline Species & \multicolumn{2}{l}{ Range of diameters $(\mathrm{cm})$} & \\
\cline { 2 - 4 } & Small diameters & medium diameters & large diameters \\
\hline Fagus sylvatica & $11-22$ & $22-28$ & $31-42$ \\
Acer pseudoplatanus & $12-19$ & $20-30$ & $31-41$ \\
Abies alba & $7-14$ & $15-20$ & $21-32$ \\
Pseudotsuga menziesii & $9-20$ & $21-32$ & $32-50$ \\
\hline
\end{tabular}


not possible to distinguish between age and size effects. On the contrary, for the other species there was no difference in tree age between the diameter classes of a given species (assessed statistically with ANOVAs).

\subsection{CT scanning and image processing}

The discs were scanned twice. A first scan was performed after less than one week of storage in a plastic bag inside a cold room after harvesting. We assumed that, in the middle of the discs, the moisture content of wood was still representative of what it was in the standing tree. The second scan was performed in the oven-dry state, after $24 \mathrm{~h}$ of drying at $105^{\circ}$ and the observation of a constant weight. The CT scanner settings and the method for processing the images are described in Longuetaud et al. (2016).

As a result of the image processing, the discs were divided into tangential bands of mean width equal to one centimetre in the fresh state (the remaining area near the pith being larger than one centimetre to complete the radius), as it is illustrated in Fig. 1. The width of the tangential bands in the dry state was computed by taking into account the shrinkage.

The advantage of this method in comparison with more classical radial sampling (e.g. increment cores or radial strips) is that each tangential band integrates the azimuthal variations at the disc level, which are potentially important depending on the growth conditions (Osazuwa-Peters et al. 2014). Another advantage of this destructive sampling is that we are sure to analyse the radial variations from the pith to the bark, which is often challenging with increment cores sampled directly in standing trees.

\subsection{Computation of BSG and $\mathrm{RWC}_{L}$}

The present paper focuses on two properties, basic specific gravity (BSG) and relative water content of lumens

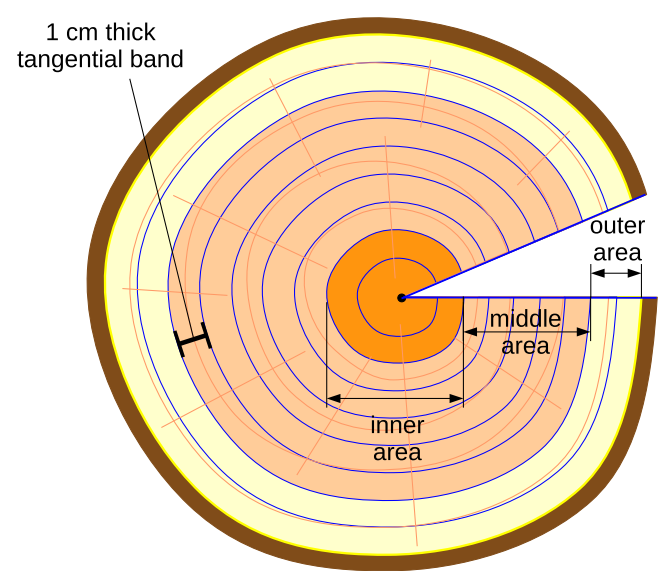

Fig. 1 Division of the discs into 1-cm-thick tangential bands and into inner, middle and outer areas
$\left(\mathrm{RWC}_{L}\right)$, whose calculations from CT images are detailed in Longuetaud et al. (2016). Both properties were computed for each tangential band of each disc.

BSG is the ratio of oven-dry weight over volume in the fresh state (1). The computation was done assuming that the longitudinal shrinkage was insignificant.

$\mathrm{BSG}=\frac{W_{0}}{V_{g}} \cdot \frac{1}{\rho_{\text {water }}}$

where $V_{g}$ is the volume at green state, $W_{0}$ is the weights at oven-dry state and $\rho_{\text {water }}$ is the density of water.

$\mathrm{RWC}_{L}$ is the proportion of the lumen volume that is occupied by free water (2). This computation assumes a constant density of cell-walls of $1500 \mathrm{~kg} \cdot \mathrm{m}^{-3}$ and a moisture content at fibre saturation point (i.e. the point at which all water is bound in the cell walls and the lumens are empty) of $30 \%$.

$\mathrm{RWC}_{L}=\frac{W_{\text {water, } g}-W_{\text {water }, F S P}}{W_{\text {water,sat }}-W_{\text {water, } F S P}} \cdot 100$

where $W_{\text {water, } g}, W_{\text {water, } F S P}$ and $W_{\text {water, } s a t}$ are respectively the weight of water in the green state, at fiber saturation point and at full saturation.

To calculate the disc averages, the volumes and weights of the tangential bands were summed and substituted into Eqs. 1 and 2. The stem averages were calculated in the same way by summing the volumes and weights of truncated cones centered on each disc (Longuetaud et al. 2016).

\subsection{Statistical analysis}

To facilitate the comparison of our results with the literature, the average values of three radial areas (inside, middle and outside) were computed for each disc at $1.3 \mathrm{~m}$ height for A. alba and P. menziesii, at $2 \mathrm{~m}$ height for $F$. sylvatica, A. pseudoplatanus and $Q$. petraea/robur: the inside area value was obtained by averaging the two innermost bands, the outside area value by averaging the two outermost bands and the middle area value by averaging the remaining bands (Fig. 1). Since the bands were $1 \mathrm{~cm}$ width in average, the resulting data should be comparable to those of Woodcock and Shier (2002), Woodcock and Shier (2003) and Plourde et al. (2015) who measured specific gravity on 2-cm core segments and evaluated radial variations using the inside segment, outside segment and average of all other segments. Inner and outer wood areas were also based on 2-cm core segments in Bastin et al. (2015).

Variations with height were analysed in the same manner by dividing the stem in four vertical sections: (A) ground level (below $30 \mathrm{~cm}$ height), (B) bottom of the stem $(1.3$ $\mathrm{m}$ height for A. alba and P. menziesii, $2 \mathrm{~m}$ height for $F$. 
sylvatica, A. pseudoplatanus and $Q$. petraea/robur), (C) remaining stem section up to crown base height, (D) inside the live crown.

Pairwise comparisons between groups (radial areas or vertical sections) were done with paired Student's $t$ test adjusted using Bonferroni correction for multiple comparisons (pairwise $t$ test).

To complete the information given by the above analyses, radial and vertical curves of variations per tree and the corresponding trends obtained by LOESS smoothing are given in Appendices A and B.

\section{Results}

\subsection{Radial variations}

The radial variations of BSG and $\mathrm{RWC}_{L}$ observed at $1.3 \mathrm{~m}$ height for A. alba and P. menziesii or at $2 \mathrm{~m}$ height for the other species are summarised in Fig. 2.

\subsubsection{Basic specific gravity}

An overall radial increase in BSG from pith to bark was observed for F. sylvatica, A. pseudoplatanus and P. menziesii (with differences in BSG from inner to outer areas of respectively $+0.017, p=0.001,+0.044, p<0.001$ and $+0.065, p<0.001$ ), whereas radial decreases were observed for $Q$. petraea/robur and A. alba (respectively $-0.075, p=0.107$ and $-0.023, p=0.010)$.

For $P$. menziesii, A. pseudoplatanus and $Q$. petraea/robur, the patterns of radial variations of BSG

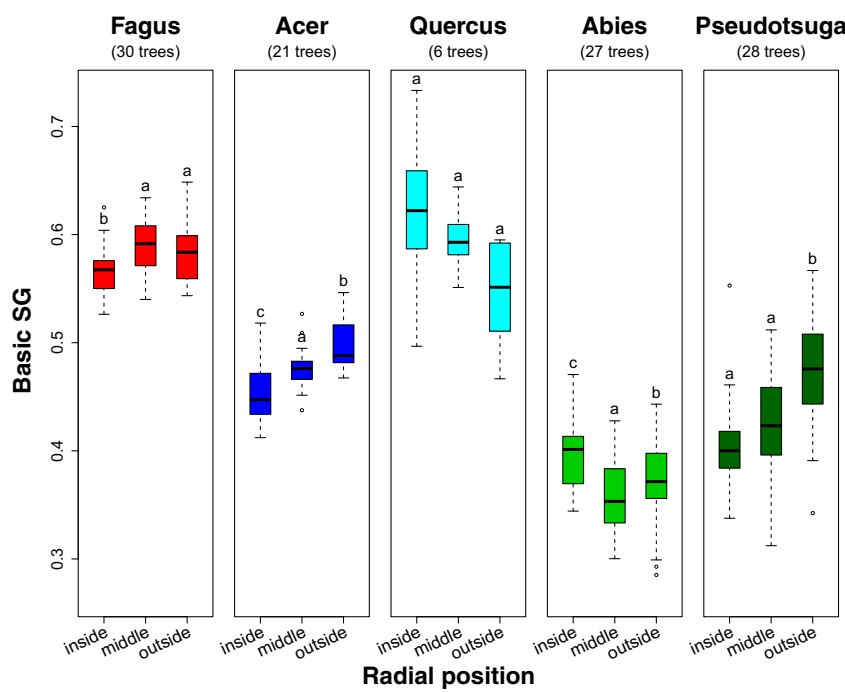

Fig. 2 Radial variations of basic specific gravity $(B S G)$ and relative water content of lumens $\left(R W C_{L}\right)$ per species at $1.3 \mathrm{~m}$ height for Abies alba and Pseudotsuga menziesii, at $2 \mathrm{~m}$ height for Fagus sylvatica, Acer pseudoplatanus and Quercus petraea/robur. The inside area were clear (although not statistically significant for $Q$. petraea/robur, probably due to the small sample size for this species) and for these species no significant size effect was observed on the radial patterns (not tested for $Q$. petraea/robur).

Regarding the particular case of $F$. sylvatica, the overall radial increase in BSG from pith to bark was due to the inside area that showed statistically significant lower values than the two other. However, for this species, a size effect seemed to occur (Fig. 3). Indeed, for the smallest trees, a radial increase was observed with a statistically significant difference between the outside and inside areas (difference in BSG of $+0.030, p=0.003$ ); for the intermediate size class, the increase was still visible between the middle and inside areas $(+0.028, p=0.005)$ but the beginning of decrease was observed between the middle and outside areas $(-0.014, p=0.090)$; this decrease at the outside part of the stem was even more visible for the biggest trees $(-0.017, p=0.014)$. To summarize, the corewood of $F$. sylvatica showed lower BSG values than the outerwood but it was not possible to conclude that an overall radial increase or decrease exists for this species due to the observation of a tree size effect.

The radial variation of BSG from pith to bark for $A$. alba showed an U-shaped pattern with a strong decrease between the inside and middle areas $(-0.037, p<0.001)$ followed by a slight increase between the middle and outer areas $(+0.014, p=0.013)$, which was significant for the smallest trees (Fig. 3) and for all the trees taken together (Fig. 2). For the medium and big trees, a strong radial decrease in BSG from pith to bark was observed due to the corewood (inside area) being significantly denser than

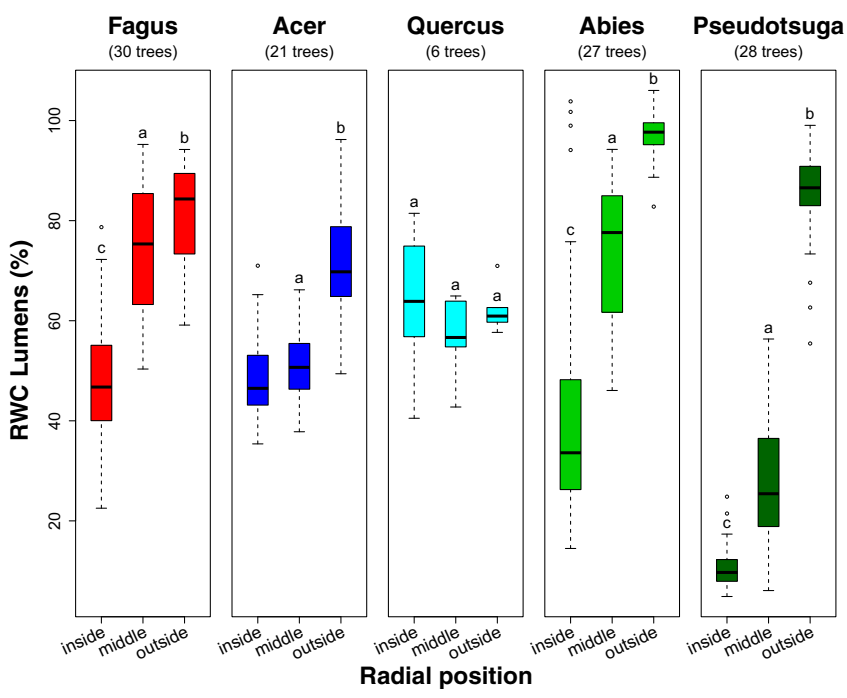

includes the two innermost 1-cm-thick bands, the outside area includes the two outermost centimetres, and the middle area includes the remaining part. The letters above the boxplots identify the statistically significant different groups according to pairwise $t$ tests 

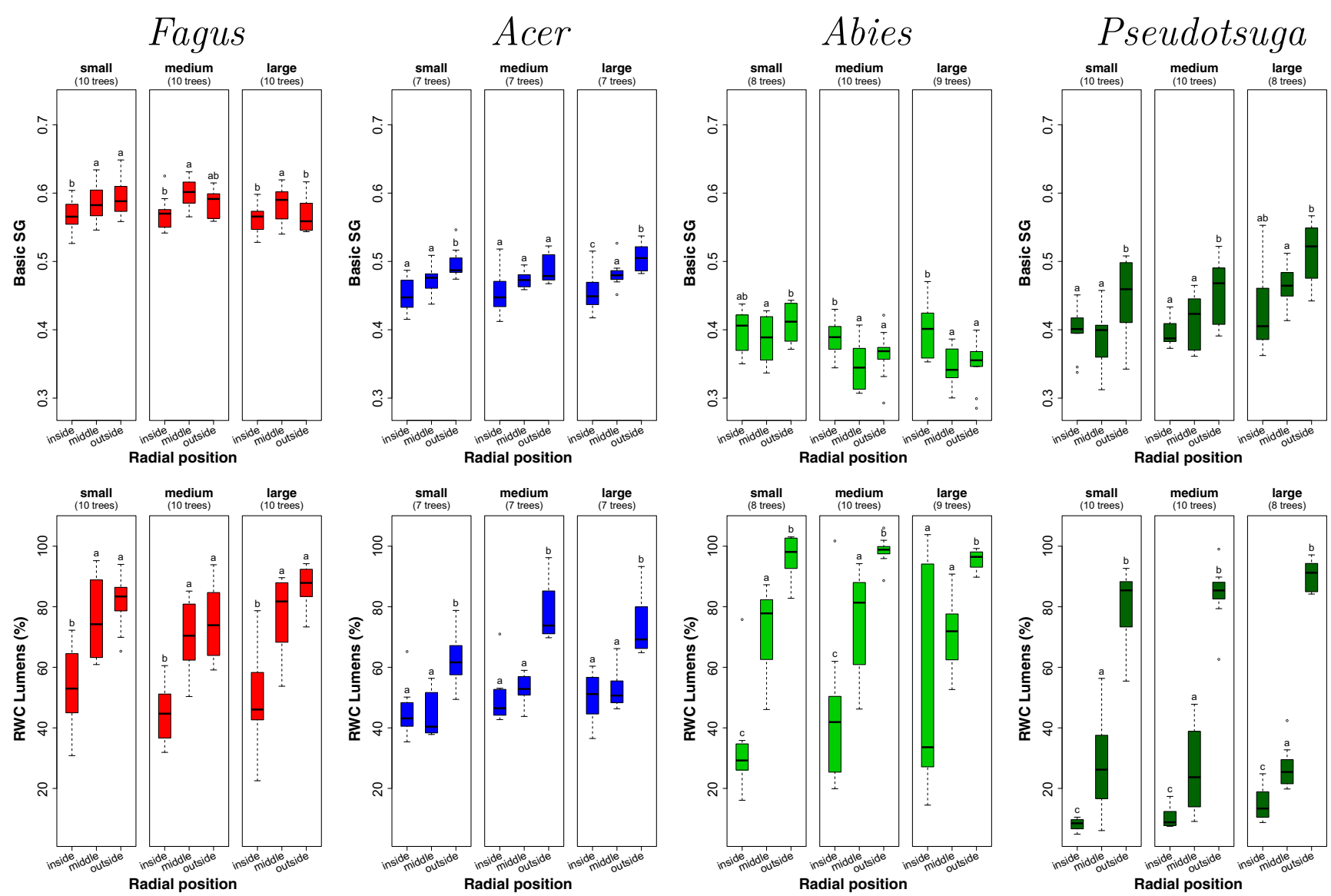

Fig. 3 Radial variations of basic specific gravity $(B S G)$ and relative water content of lumens $\left(R W C_{L}\right)$ for Fagus sylvatica, Acer pseudoplatanus, Abies alba and Pseudotsuga menziesii for three classes of diameter at breast height (small, medium, large). The inside area
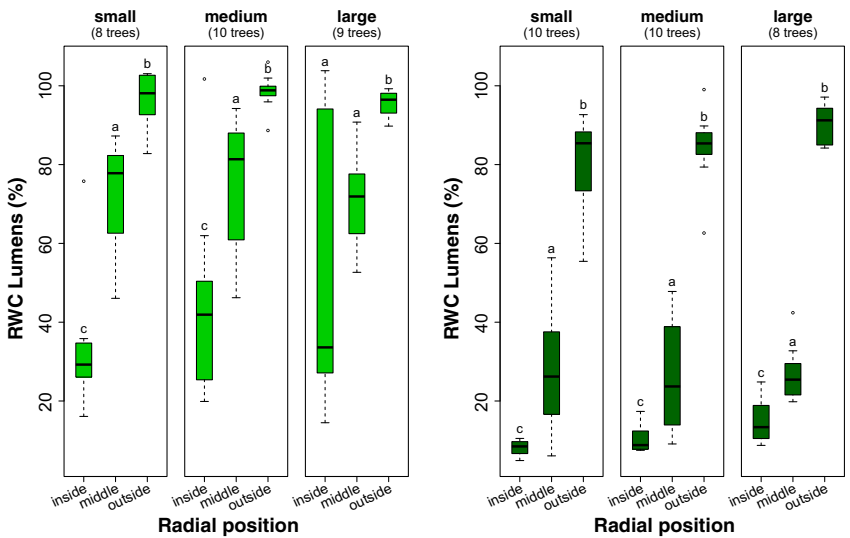

includes the two innermost 1 -cm-thick bands, the outside area includes the two outermost centimetres, and the middle area includes the remaining part. The letters above the boxplots identify the statistically significant different groups according to pairwise $t$ tests

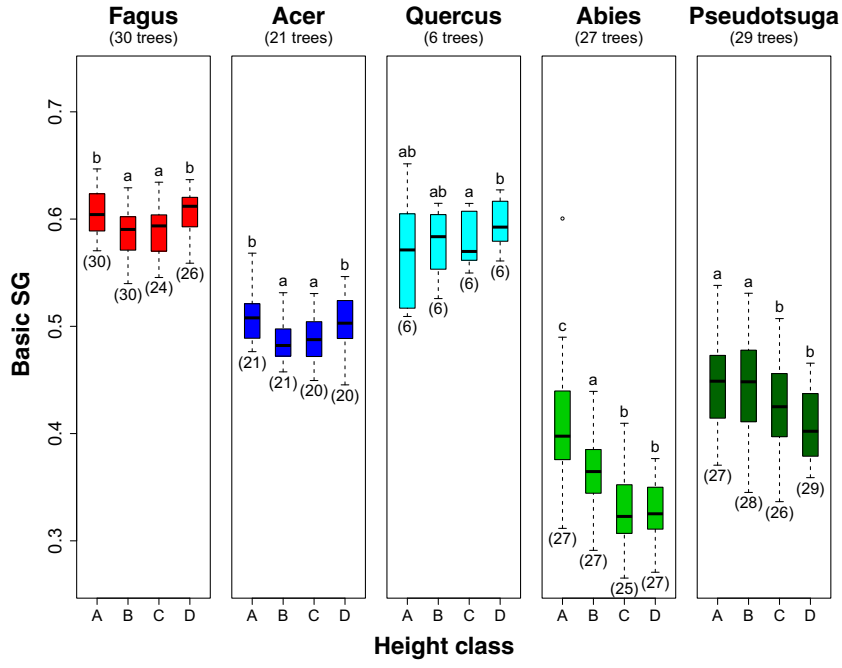

Fig. 4 Vertical variations of basic specific gravity $(B S G)$ and relative water content of lumens $\left(R W C_{L}\right)$ per species: $(A)$ ground level $(<0.50 \mathrm{~m}),(B)$ stem bottom $(1.30 \mathrm{~m}$ for softwood species, $2 \mathrm{~m}$ for hardwood species), $(C)$ below crown base height, $(D)$ inside the crown. For several trees, there was no measurement in either of the two upper

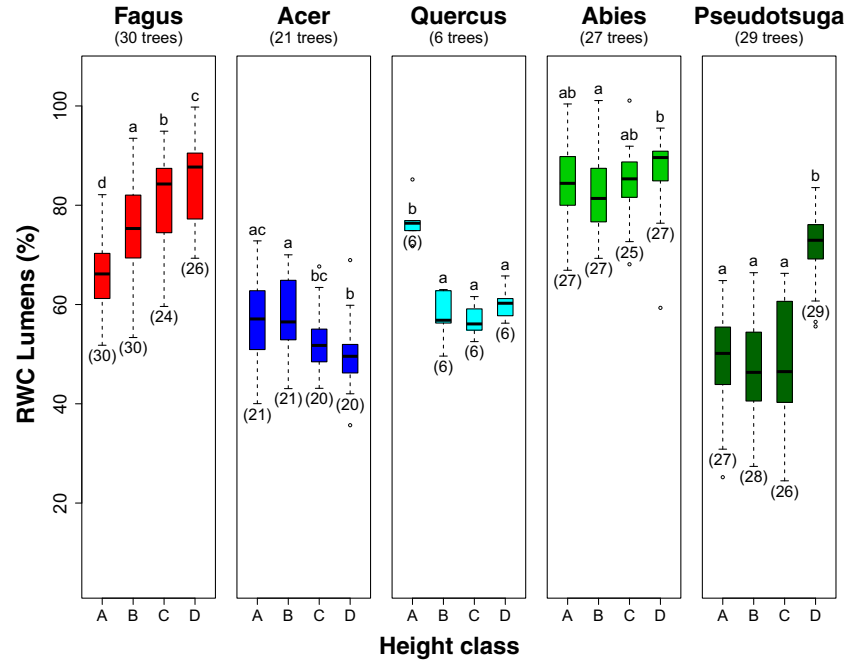

compartments. The bracketed numbers below the whiskers indicate the actual number of trees for each box. The letters above boxplots identify the statistically significant different groups according to pairwise $t$ tests 
the outerwood (middle and outside areas). For the smallest trees, the middle and outside areas were denser than for other trees. These variations were mainly due to the ring width effect: indeed, contrary to the other species, BSG at $1.30 \mathrm{~m}$ height for $A$. alba trees was significantly negatively correlated to the radial growth rate assessed through the ratio DBH/Age ( $\left.r_{\text {Pearson }}=-0.55, p=0.002\right)$.

\subsubsection{Relative water content of lumens}

Radial increases in $\mathrm{RWC}_{L}$ from pith to bark were observed for all species except $Q$. petraea/robur (Fig. 2). For $F$. sylvatica, the inside area showed relatively low values of $\mathrm{RWC}_{L}$ compared with the middle and outside areas (48, 74 and $81 \%$, respectively), whereas for A. pseudoplatanus it was the outside area which showed relatively high values compared with middle and inside areas (72, 50 and $49 \%$, respectively). The differences in $\mathrm{RWC}_{L}$ between the corewood and outerwood were the highest for $P$. menziesii ( $11 \%$ inside, $85 \%$ outside) and A. alba (44\% inside and $97 \%$ outside). No significant radial variation was observed for $Q$. petraea/robur, which showed relatively homogeneous $\mathrm{RWC}_{L}$ in the radial direction in comparison with other species. No major size effect was observed except maybe for A. alba which showed a particularly high variation of $\mathrm{RWC}_{L}$ for the inside area of the biggest trees (Fig. 3). These high variations were due to the presence of some $A$. alba trees showing wetwood in the inner wood area of their stem whereas the other trees had rather dry inner wood area (Appendix A).

\subsection{Vertical variations}

The vertical variations of $\mathrm{BSG}$ and $\mathrm{RWC}_{L}$ observed for each species are summarised in Fig. 4.

$T$ test paired comparisons were used to compare breast height measurements (1.30 m height) with mean values obtained on the basis of measurements done all along the stem (Table 4) and thus to assess the representativeness of breast height in the stem.

\subsubsection{Basic specific gravity}

For $F$. sylvatica and A. pseudoplatanus, the variations of BSG with height were U-shaped with the highest values observed at the bottom of the stem (0.607 for $F$. sylvatica and 0.505 for A. pseudoplatanus) and within the living crown (0.605 and 0.505 respectively). For $A$. alba and $P$. menziesii, BSG decreased from the stem bottom ( 0.408 and 0.447 respectively) to the crown base $(0.333$ and 0.424$)$ and into the live crown (0.328 and 0.409). No significant vertical variation was observed for $Q$. petraea/robur $(0.571$ at the stem bottom, 0.595 within the crown).

Except for A. alba and P. menziesii, for which BSG at breast height was significantly greater than whole-stem mean BSG, the differences between breast height and whole stem measurements of BSG were not statistically significant since the vertical variations of BSG were in general relatively low (Table 4).

\subsubsection{Relative water content of lumens}

A significant increase in $\mathrm{RWC}_{L}$ was observed for $F$. sylvatica with height in the stem (from 67 to $86 \%$ ). Although less pronounced, the opposite was observed for A. pseudoplatanus with a decrease in $\mathrm{RWC}_{L}$ with height in the stem (from 57 to $50 \%$ ). Q. petraea/robur was characterised by high values of $\mathrm{RWC}_{L}$ at ground level (77\%), whereas $P$. menziesii had high values at the top of the stem (72\%). No clear pattern of variation was observed for A. alba.

The differences between values computed at breast height and averaged along the whole stem were significant except for A. pseudoplatanus. Mean whole-stem $\mathrm{RWC}_{L}$ was significantly lower than breast height measurements for $Q$. petraea/robur and significantly higher for $F$. sylvatica, A. alba and P. menziesii (Table 4).

\subsubsection{Relationship between radial and vertical variations}

Since the variations with height could result from radial variations, due to the proportions of the different types of
Table 4 Means and standard deviations of BSG and $\mathrm{RWC}_{L}$ by species for whole stems and at breast height (estimations by interpolation for Fagus sylvatica, Acer pseudoplatanus and Quercus petraea/robur, and by measurements for Abies alba and Pseudotsuga menziesii)

\begin{tabular}{|c|c|c|c|c|c|c|}
\hline \multirow[t]{2}{*}{ Species } & \multicolumn{3}{|l|}{ BSG } & \multicolumn{3}{|l|}{$\mathrm{RWC}_{L}(\%)$} \\
\hline & Whole stem & Breast height & $t$ & Whole stem & Breast height & $t$ \\
\hline Fagus sylvatica & $0.59(0.02)$ & $0.59(0.02)$ & NS & $80(7)$ & $73(9)$ & $* * *$ \\
\hline Acer pseudoplatanus & $0.49(0.02)$ & $0.49(0.02)$ & NS & $54(6)$ & $58(8)$ & NS \\
\hline Quercus petraea/robur & $0.58(0.03)$ & $0.58(0.04)$ & NS & $58(3)$ & $64(5)$ & $* * *$ \\
\hline Abies alba & $0.35(0.04)$ & $0.37(0.04)$ & $* * *$ & $86(5)$ & $83(7)$ & $* * *$ \\
\hline Pseudotsuga menziesii & $0.42(0.04)$ & $0.44(0.05)$ & $* * *$ & $52(11)$ & $47(10)$ & $* * *$ \\
\hline
\end{tabular}

The stars indicate the significance of paired comparisons between breast height measurements and whole stem measurements $(* * * p$ value $<0.1 \%$, NS: $p$ value $\geq 5 \%$ ) 


\section{Fagus sylvatica}
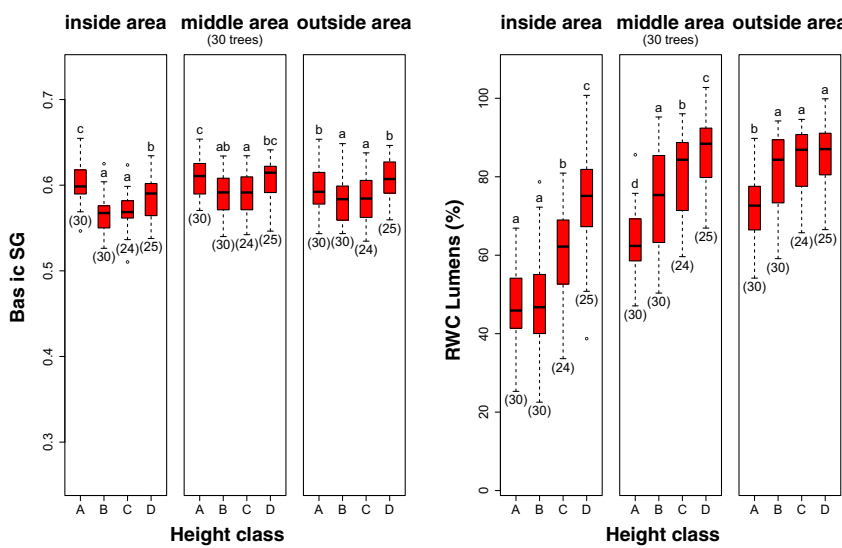

Acer pseudoplatanus
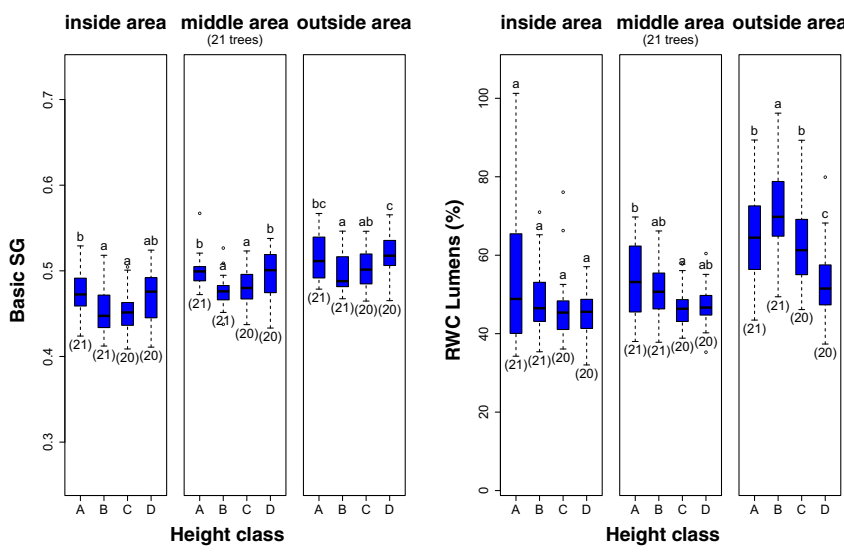

Quercus petraea/robur
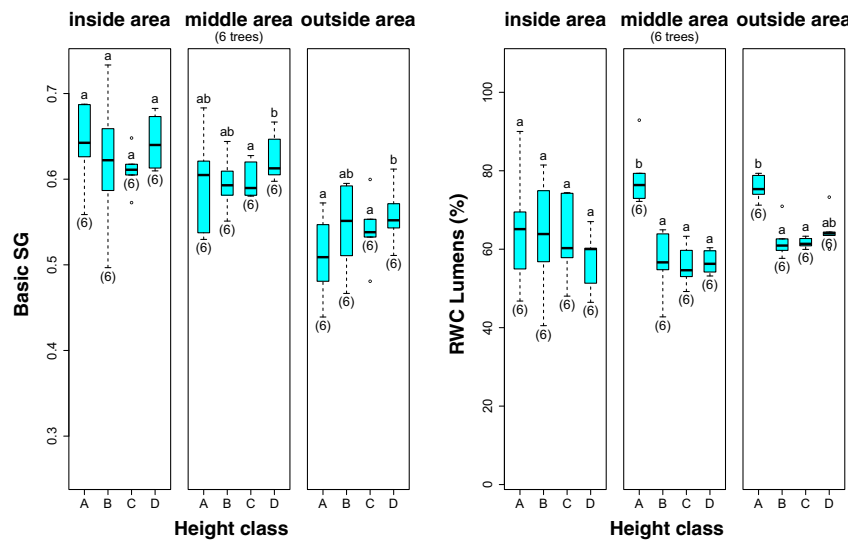

Fig. 5 Vertical variations of basic specific gravity $(B S G)$ and relative water content of lumens $\left(R W C_{L}\right)$ per species for each radial areas. The inside area includes the two innermost $1-\mathrm{cm}$-thick bands, the outside area includes the two outermost centimetres, and the middle area includes the remaining part. $A$ ground level $(<0.50 \mathrm{~m}), B$ stem bottom (1.30 m for softwood species, $2 \mathrm{~m}$ for hardwood species), $C$
Abies alba
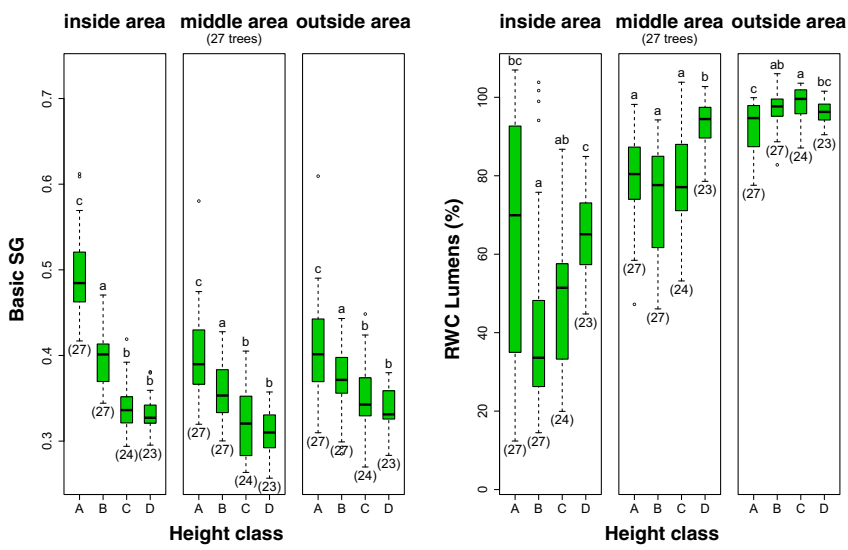

\section{Pseudotsuga menziesii}
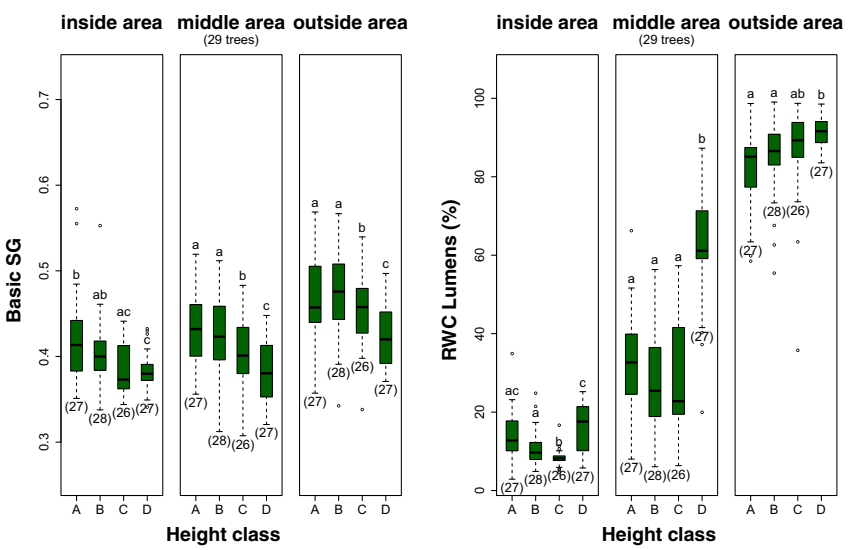

below crown base height, $D$ inside the crown. For several trees, there was no measurement in either of the two upper compartments. The bracketed numbers below the whiskers indicate the actual number of trees for each box. The letters above boxplots identify the statistically significant different groups according to pairwise $t$ tests 
wood that might change with height (e.g. proportions of corewood for BSG or sapwood for $\mathrm{RWC}_{L}$ ), the variations with height were also studied within each radial area: inside, middle and outside (Fig. 5).

For BSG, the shapes of the variations with height for a given species were about the same whichever radial area was considered. Variations with height of $\mathrm{RWC}_{L}$ within each radial area were more complicated to analyse. The relatively high values of $\mathrm{RWC}_{L}$ observed at the ground level for $Q$. petraea/robur (Fig. 4) were mostly related to the middle and outside areas (Fig. 5). The higher values of $\mathrm{RWC}_{L}$ that were observed at the top of the stem for $P$. menziesii were only related to the middle area. The high variation of $\mathrm{RWC}_{L}$ that was observed in the inside area for the biggest trees of A. alba (Fig. 3) was located mainly at the ground level.

\section{Discussion}

\subsection{Comparison between our data and the theories/models/patterns of wood density radial variations proposed in the literature}

Table 5 summarizes the comparison of our results with different theories found in the literature.

Radial variations in BSG are often associated with successional status of species and associated strategies (Woodcock and Shier 2002; Schüller et al. 2013). Numerous studies, generally based on tropical tree species, report that early-successional species are characterised by fast growth associated with the production of low density wood at the beginning of the tree life, and then by the production of denser wood when the tree becomes older (Osunkoya et al. 2007; Schüller et al. 2013; Plourde et al. 2015). In contrast, late-successional species start with the production of dense wood and then show radial decrease in density. Woodcock and Shier (2002), based on both tropical and temperate species, have proposed a model of radial variations of BSG with a threshold of initial BSG at about 0.55 such that: species around 0.55 would have absent or very limited radial trends; species above 0.55 would show radial decrease in density associated with late-successional characteristics; and inversely species below 0.55 would show radial increase in density associated with early-successional characteristics. According to Woodcock and Shier (2002), this pattern would be valid both for hardwood and softwood species but with a lower threshold at around 0.40 for softwoods. Plourde et al. (2015) have proposed slightly different thresholds with a radial increase for species below 0.5 in BSG and a decrease for species above 0.7 . Mainly based on softwood species, Lachenbruch et al. (2011) have proposed a typical radial pattern (TRP) with a lower specific gravity in the corewood than in the outerwood. In contrast to Woodcock and Shier (2002), who distinguished two patterns of radial variation for softwoods (increasing BSG vs. decreasing BSG), the TRP retains only one main pattern (increasing BSG). Lastly, the relationship between wood density and the successional status of a species was also observed by Poorter (2008) who reported that the cell-wall fraction, proportional to BSG (Longuetaud et al. 2016), decreases with the light requirement of the species.

A possible functional interpretation of the radial patterns was proposed by Lachenbruch et al. (2011). According to this hypothesis, radial trends in different wood properties are related to the modification of the plant mechanical and hydraulic needs with increase in size. To withstand wind loads for example, a small tree would rely on its deformability to avoid wind loads while a big tree with a large diameter and thus high bending resistance will resist wind loads through mechanical strength (Badel et al. 2015). One may suppose that change in mechanical loads during the ontogeny will be different for pioneer and understorey species. While young pioneer tree will preferentially need to invest in rapid growth rather than in wood density to occupy the space and quickly achieve a high bending resistance, an understorey species in contrast may need high density to increase resistance to biotic damages (Plourde et al. 2015) and falling woody materials while growing slowly under the canopy. High wood density in juvenile trees is probably a strategy of late-successional species waiting for their turn (Woodcock and Shier 2002; Chave et al. 2009).

When referring to the strict definition of inner and outer wood used by Woodcock and Shier (2002) and Plourde et al. (2015) (i.e. 2-cm inner and 2-cm outer segments) and presenting the results in the same form they used (Fig. 6), most $F$. sylvatica and A. pseudoplatanus trees and a majority of $P$. menziesii trees were characterised by a radial increase from inner to outer areas in BSG, whereas most Q. petraea/robur and $A$. alba trees showed a radial decrease. However, by removing the $2-\mathrm{cm}$ inner segment, the radial variations of BSG were reversed for F. sylvatica and A. alba (Table 5). In addition, the mean inner BSG was very near the threshold of 0.4 both for $A$. alba and $P$. menziesii. Thus, referring very strictly to Woodcock and Shier (2002), their model fitted to our data only for A. pseudoplatanus and $Q$. petraea/robur. But from our results (Table 5), it appeared that existing patterns are complex and thus difficult to summarize through a model of radial variations.

For some species, it is not relevant to consider only inner and outer wood regardless of what happens in-between. For some tropical species, Osazuwa-Peters et al. (2014) have identified U-shaped patterns for wood BSG. In our case, $F$. sylvatica and A. alba were both characterised by contrasting values of BSG in the inner wood compared with the middle and outer areas (i.e. relatively low density for inner wood of $F$. sylvatica and relatively high density for inner 


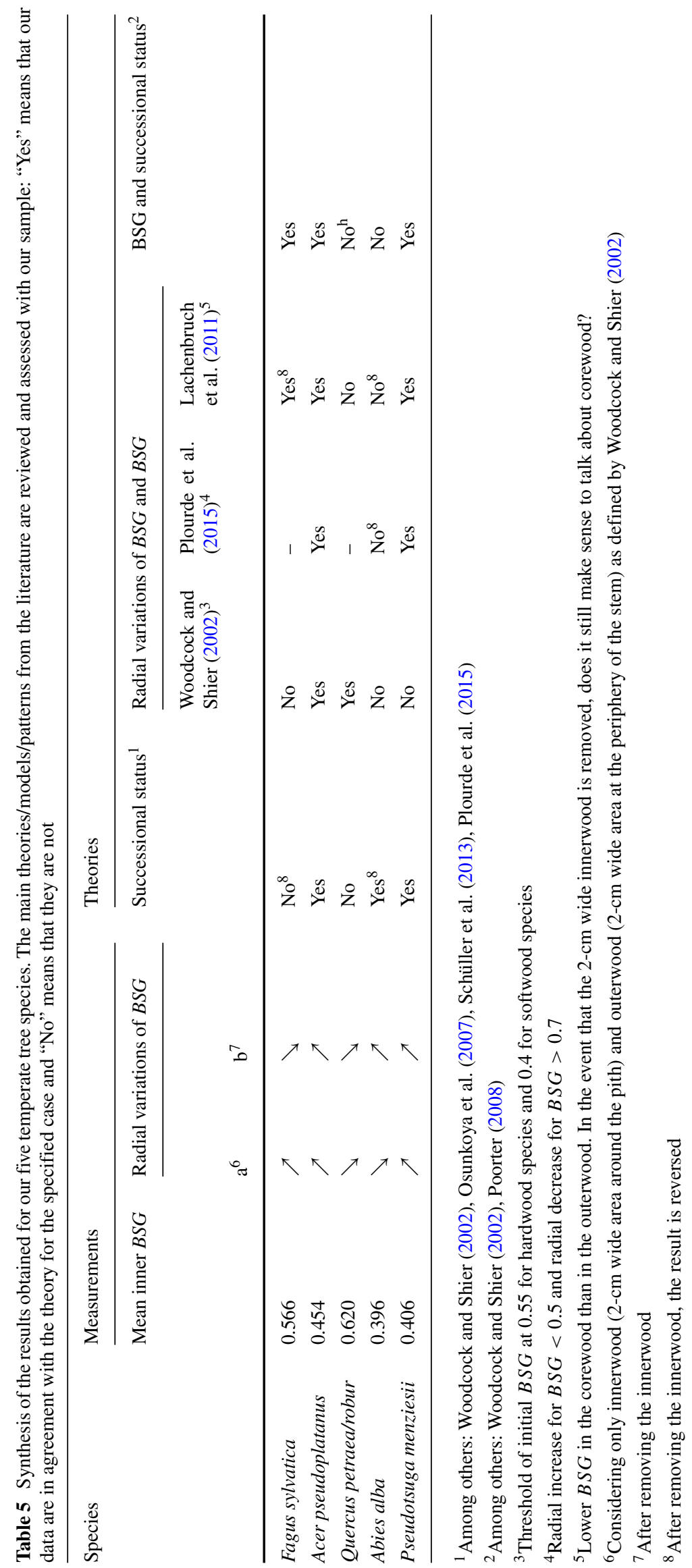


wood of A. alba) resulting in U-shaped radial patterns (see Fig. 2 and Appendix A page 5). Consequently, by considering only inner and outer areas, an overall radial increase in density was observed for $F$. sylvatica, whereas a decrease was observed for A. alba. For these two species, the models of radial variations from the literature fitted our data only after removing the inner wood area in some cases (Table 5). Indeed, without considering the inner wood area, we could observe a radial increase in density for A. alba and a radial decrease for $F$. sylvatica (although these variations were not always statistically significant and depended strongly on the size and age of trees), and therefore the theories proposed by Plourde et al. (2015) and by Lachenbruch et al. (2011) would become in agreement with our data. Hence, our results do not contradict the radial variations of BSG usually observed in softwoods, described by Lachenbruch et al. (2011), for which, after an initial decrease for the first 5-20 growth rings (except in some Pine species), there is a rapid increase with ring number followed by a levelling off.

A. alba, a shade-tolerant species, is known to have a very slow radial growth during the first years of development. In general, for softwood species there is a negative correlation between annual ring width and wood density since it is mainly the width of the earlywood, which is less dense than latewood, that is modified (Nepveu 1994). This could explain the particularly higher wood density of inner wood in comparison with outer wood observed for A. alba. The ring width effect could also explain the radial increase in density observed at the external part of the stem (outside area), even more obvious for small trees than for big ones, probably due to a radial decrease in ring width with cambial age.

The clear increase of BSG that we observe for P. menziesii with increasing radius is coherent with the results of Gartner et al. (2002) and Filipescu et al. (2014). Both reported a radial increase of density with cambial age, except for the first rings near the pith, associated with a decline of ring width. Gartner et al. (2002) observed also that, from about the fifth ring, the latewood proportion (based on either ring area or ring width) increased with cambial age.

Regarding F. sylvatica, the radial decrease in BSG observed at the external part of the stem was significant only for the biggest trees in our dataset, which suggested a tree size effect. Other studies have reported a radial decrease in density for this species. For example, Bontemps et al. (2013) observed a general slow decreasing trend of mean ring specific gravity with increasing ring number when the 20 first growth rings were removed from the dataset. For this species, contradictory results were previously obtained, showing either higher or lower density in juvenile wood compared with mature wood (Nepveu 1981), whereas, for

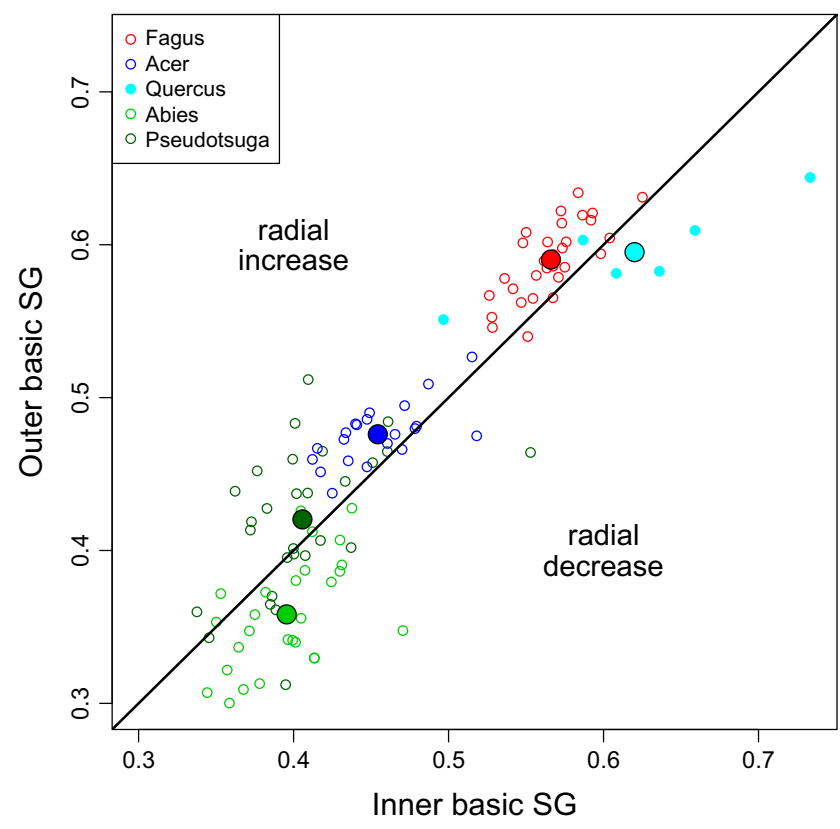

Fig. 6 Basic specific gravity $(B S G)$ for the outer area $v s$ the inner area at $1.30 \mathrm{~m}$ height for softwood species, and $2 \mathrm{~m}$ for hardwood species. Each point represents a tree. Larger circles show the barycentre of each species. The solid diagonal line is the 1:1 line

Quercus sp., the radial decrease in BSG from pith to bark is well-known (e.g. Wassenberg et al., 2015).

Last, the relationship reported by Woodcock and Shier (2002), Poorter (2008) and some other authors, mainly for tropical species but for some temperate species as well, between wood density and the successional status of species was not applicable for two of our five temperate species: $Q$. petraea/robur and A. alba. Q. petraea/robur, which had relatively high BSG above 0.55 , and which was characterised by a radial decrease in density is not a late-successional species since it is rather shade-intolerant (Niinemets and Valladares 2006). In contrast, A. alba, with a BSG below 0.40 and a trend toward a radial increase in BSG, due probably to a decrease in ring width for the highest ring numbers, is a shade-tolerant species.

\subsection{Representativeness of breast height measurements}

For all species except $Q$. petraea/robur, BSG was significantly higher at the bottom of the stem (i.e. ground level) in comparison with other parts of the stem below the living crown. The difference between BSG measured at $1.30 \mathrm{~m}$ height and average BSG computed from the whole stem was only significant for A. alba and for P. menziesii. For both species, breast height measurements would overestimate the average whole stem BSG by $5 \%$. For F. sylvatica, A. pseudoplatanus and A. alba, BSG showed a U-shaped pattern of variation with height and the density was approximately the same at the bottom of the stem and within the living crown. 
This U-shaped pattern is in accordance with the results from Repola (2006) for pine and birch. Wassenberg et al. (2015) also observed a vertical U-shaped pattern for Quercus. Previous studies have pointed out that both radial and vertical variations should be considered in order to obtain correct biomass and carbon flux estimates (Repola 2006; Nogueira et al. 2008; Bastin et al. 2015; Wassenberg et al. 2015). Nevertheless, wood density is most of the time measured on wood increment cores taken at breast height and the results are applied to the whole tree volume assuming that wood density is homogeneous for the whole tree (i.e. within stem and branches). Wassenberg et al. (2015) have compared different sampling strategies for biomass estimation and the best sampling position for increment cores was at $1 / 3$ of the tree height and at $2 / 3$ of the radial distance from pith to bark. With respect to our five temperate tree species, breast height measurements of BSG were in fairly good agreement with the average whole stem BSG, which means that the biomass of stems would be correctly estimated based on breast height density measurements for these species. However, we must bear in mind that a small systematic bias can lead to significant errors in estimating biomass (and carbon stock) when working at broad scales such as a regional, national or international forest resource. Moreover, the variability of wood density is probably even greater between the stem and branches than in the stem itself and the measurements at breast height are really questioning about their representativeness at the level of the whole tree. In contrast, $\mathrm{RWC}_{L}$ values measured at breast height were overall not representative of the average stem values due to a higher variability along stems than for BSG.

\subsection{Relationship between vertical and radial variations}

The diameter of a stem decreases with increasing height, and as a result of this stem taper, radial variations of wood properties are responsible for a part of observed vertical variations:

(a) A property depending on the distance to the pith (e.g. varying from juvenile to mature wood) may change with height. For instance, in Fig. 7a, the grey levels lighten with the distance from the pith and the mean grey level of a disc will darken from the bottom to the top of the stem. Considering separately the inner and outer parts of each disc, the outer area darkens with increasing height while the inner area remains constant.

(b) A property depending on the distance to the cambium (e.g. varying from sapwood to heartwood) would present the map shown in Fig. 7b. If the grey levels darken from pith to bark, the mean grey level of a disc would also darken from bottom to top. The inner area darkens with increasing height and the outer area remains constant.
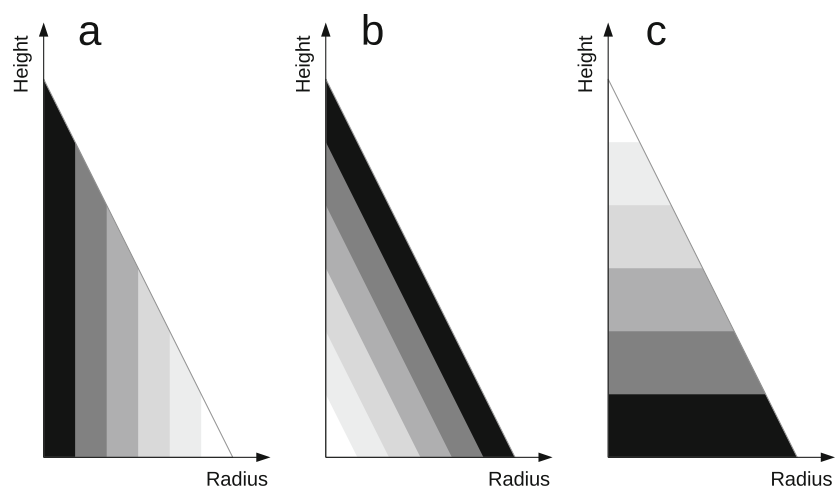

Fig. 7 Theoretical variations with height and radius of a property depending $\mathbf{a}$ on the distance to the pith, $\mathbf{b}$ on the distance to the cambium and $\mathbf{c}$ on the height (see explanations in the text)

(C) A property depending only on height would lead to the map presented in Fig. 7c with disc average, inner area and outer area varying in the same way.

Actually, the spatial distribution of wood properties presents much more complex patterns, with a mixture of (a), (b) and (C) patterns and depending on many other variables (ring number, tree age...), but most of the observed cases can be connected to one of these three patterns or to a fourth one in which there is no variation at all (pattern (d)). Patterns (a) and (b) illustrate the case of a property for which vertical variations would be partly due to radial variations. Pattern (C) is the case of a property for which vertical variations would be independent of radial variations (which does not mean that there is no radial variation).

Vertical variations of BSG were clearly related to pattern (C) since, whatever the species, a similar effect of height was observed for the inside, middle and outside areas. Even if it was often combined with a radial effect, we can conclude here that an independent height effect was observed.

$\mathrm{RWC}_{L}$ showed contrasting patterns depending on the species: F. sylvatica, A. alba and P. menziesii were similar to pattern (b), with a nearly saturated area close to the bark all along the stem; A. pseudoplatanus to pattern (a), with a high water content area mostly in the outer area at the bottom of the stem; and $Q$. petraea/robur was intermediate between patterns (C) and (d), with high water content areas mainly near the stump. In the last case, there was no clear radial variation; in the two other cases the vertical variations were partly due to the radial variations.

\subsection{Underlying relationship between observed $\mathrm{RWC}_{L}$ variations within-stem and hydraulic functions of wood (conductance and capacitance)}

Water content in trees is known to vary with time. Here, we assume that $\mathrm{RWC}_{L}$ measured in winter during daylight is enough stable and representative of tree species to be considered as a specific trait. Trees measured during other 
seasons of the year, especially during the growth season, would probably show different values and distributions of $\mathrm{RWC}_{L}$.

Except for $Q$. petraea/robur, the trees showed the highest $\mathrm{RWC}_{L}$ at the outer part of the stem, even if the detailed patterns of variations were slightly different depending on the species. This observation was consistent with the general idea that water is mainly transported in the external part of the stem. Indeed, a high water content can be related to the presence of a conductive area, although it is also possible to have wet or fully saturated areas that are no longer conductive.

Gebauer et al. (2008) showed that the conducting sapwood of diffuse-porous species (including $F$. sylvatica and A. pseudoplatanus) occupied 70 to $90 \%$ of the stem crosssectional area. Under the assumption that wet areas, associated with a high level of water saturation in the lumens, are related to the presence of conductive areas, our results were in agreement with those of Gebauer et al. (2008) for $F$. sylvatica (both middle and outside areas had high values of $\mathrm{RWC}_{L}$ ) but less in agreement for A. pseudoplatanus (only the outside area had high values of $\mathrm{RWC}_{L}$ ).

In contrast, ring-porous species like oak are known to conduct water in the outermost annual growth rings (Barbaroux and Bréda 2002; Lüttschwager and Remus 2007). In our study, the water content was rather homogeneous radially for $Q$. petraea/robur, as previously shown by Fromm et al. (2001). It is also possible that the width of the outside areas ( $2 \mathrm{~cm}$ in average) was too large to distinguish only a few rings (maybe only one ring in some cases) with high $\mathrm{RWC}_{L}$ values. In addition, a question arises about the thickness of the sampled wood discs in relation to the length of the vessels, which could be embolised due to the cutting, especially for Quercus species. Quercus rubra is reported to have a maximum vessel length up to $1.34 \mathrm{~m}$ (Cochard et al. 2010). However, only a low percentage of vessels reach such lengths, for example in $Q$. robur, $70 \%$ of vessels were shorter than $4 \mathrm{~cm}$ and only $10 \%$ of vessels were longer than $20 \mathrm{~cm}$ according to Cochard and Tyree (1990).

Regarding softwood species, trees often conduct water across large cross-sections (sapwood), and heartwood is completely isolated from the water conducting network (Lüttschwager and Remus 2007). This could explain why, for softwood species, there is often a strong contrast between the moisture content of the heartwood and sapwood (e.g. Fromm et al., 2001), and thus explain the strong radial variations that were observed in our study for $A$. alba and for $P$. menziesii. Tracheids in softwoods have a maximum length of $5 \mathrm{~mm}$ (Hacke 2015) and therefore there is not a problem with possible embolized conduits due to cutting. The high variability observed for $\mathrm{RWC}_{L}$ at the bottom of the stem in the inner wood area for A. alba species was due to the presence of wetwood for some trees, which is a quite common feature for this species and which seems to be related to a disease (Bauch et al. 1979; Shortle and
Bauch 1986) and associated with acidic anaerobic bacteria (Streichan and Schink 1986).

$\mathrm{RWC}_{L}$ is quite clearly related to the capacitance function of wood since it describes the amount of stored water potentially available to buffer the fluctuations of water potential in the tissue. For softwood species, $\mathrm{RWC}_{L}$ may be used as a proxy of the percentage of the embolized tracheids in the native condition (Domec and Gartner 2002) as tracheids represent up to $90 \%$ of the tissue volume (Hacke 2015), whereas in hardwoods, the relationship with embolized conduits is more complicated because vessels represent only a small percentage of the tissue volume (Beeckman 2016).

\section{Conclusion}

Radial and vertical variations of basic specific gravity (BSG) and relative water content of lumens $\left(\mathrm{RWC}_{L}\right)$ were analysed for five temperate tree species. BSG and $\mathrm{RWC}_{L}$ were found in a previous study (Longuetaud et al. 2016) to be good candidates for the characterisation and the discrimination of species since they showed a good complementarity.

This work helps to answer the questions raised in the Introduction section:

- Data were only partially in agreement with the patterns of wood density radial variations described in the literature. The observed variations were complex, highly species dependant, and it appeared difficult to summarize our data with a typical pattern.

- Breast height measurements of BSG appeared to be a good estimator of the mean BSG of the whole stem for the three studied broadleaved species, but an overestimation of $5 \%$ was observed for softwood species. Breastheight measurements of $\mathrm{RWC}_{L}$ overestimated or underestimated the whole stem, depending on the species.

- Vertical and radial variations of BSG were found independent of each other whereas vertical variations of $\mathrm{RWC}_{L}$ were mostly due to radial variations.

In future work, typical early-successional temperate tree species should be studied in order to obtain a wide range of temperate successional status and to analyse the patterns of variations for these species.

The impact of breast height measurements should be better quantified within the framework of biomass and carbon stock estimations, particularly by considering the species of major interest for the resource evaluation, and by assessing their representativeness in comparison with whole tree measurements (i.e. including branch wood). Moreover, some questions should be further investigated: Why is BSG greater at the bottom of tree stems than above? Could it be more efficient for the tree stability (mechanical function of wood) or rather related to a higher risk of external damages at this height? 
Further study should also associate $\mathrm{RWC}_{L}$ and sap flow measurements to better understand the relationship between $R W C_{L}$ and hydraulic functions of wood.

Acknowledgements We thank all the people involved in this project, especially those who contributed to field measurements and CT scanning.

\section{Compliance with Ethical Standards}

Funding A part of the data used in this work was collected within the frame of the Modelfor 2012-2015 joint project between INRA and ONF and the research project EMERGE funded by the French National Research Agency (ANR) through its Bioenergy program. The Douglas fir data were issued from the long-term experimental network managed by the French data cooperative on forest growth (Gis-Coop). The UMR 1092 LERFoB is supported by a grant overseen by the French National Research Agency (ANR) as part of the "Investissements d'Avenir" program (ANR-11-LABX-0002-01, Lab of Excellence ARBRE).

\section{Appendix A: Radial variations per tree and species and associated radial trends per species}

Variations of basic specific gravity ( $B S G$ ) and relative water content of lumens $\left(R W C_{L}\right)$ with radius (distance to pith in $\mathrm{mm}$ ),
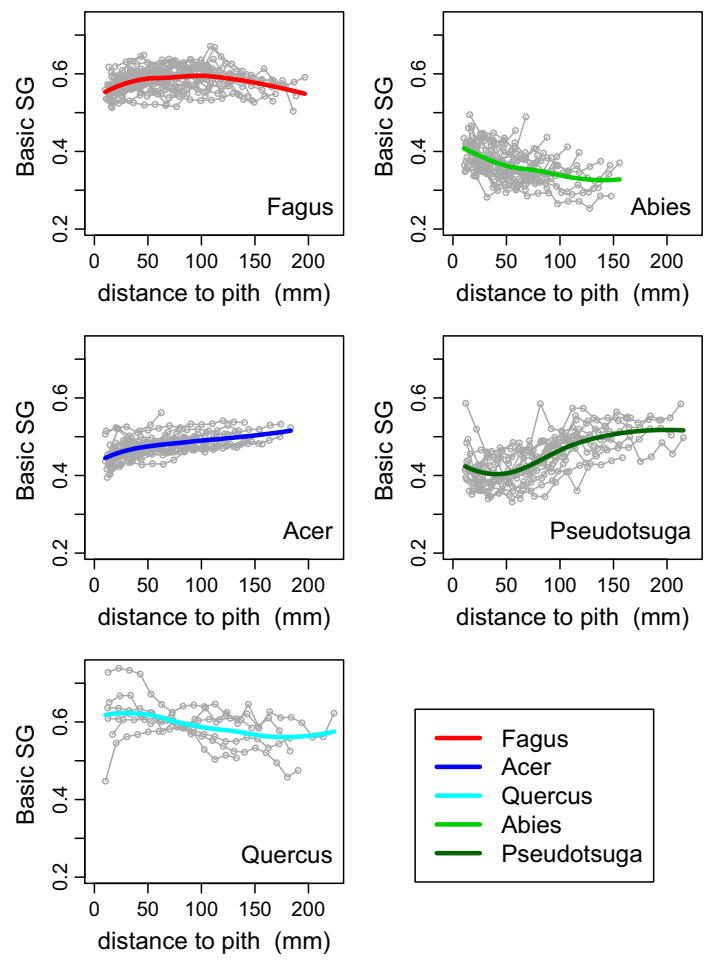

Fig. 8 Variations of basic specific gravity (BSG) with radius (distance to pith in $\mathrm{mm}$ ) at $1.3 \mathrm{~m}$ height for Abies alba and Pseudotsuga menziesii, and at $2 \mathrm{~m}$ height for Fagus sylvatica, Acer pseudoplatanus and Quercus petraea/robur. Each point represents the average of one $1 \mathrm{~cm}-$ thick tangential band; each grey curve represents one tree; the coloured solid lines show the LOESS smoothing for each species
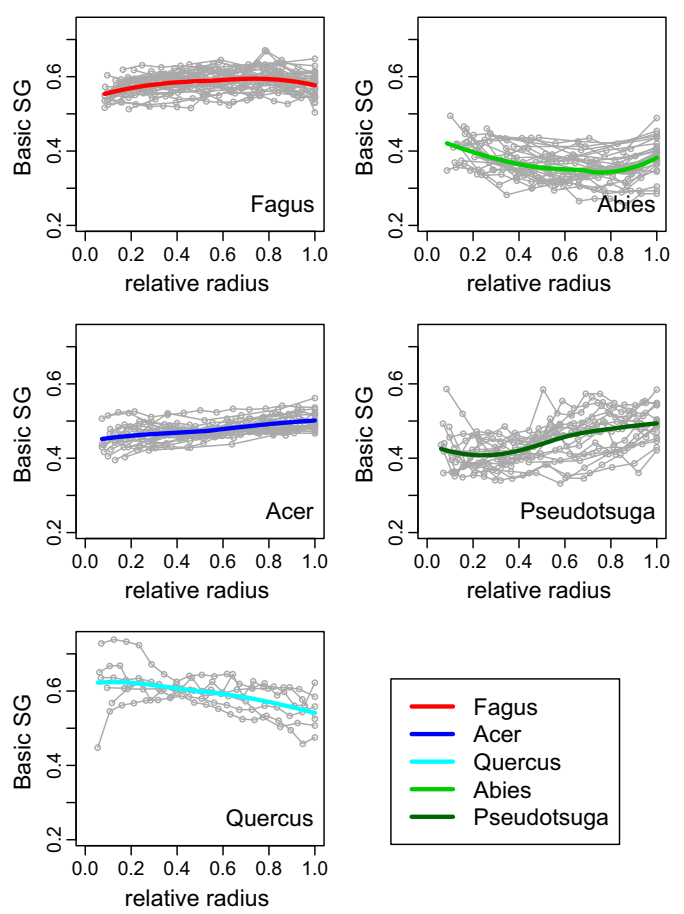

Fig. 9 Variations of basic specific gravity (BSG) with relative radius at $1.3 \mathrm{~m}$ height for Abies alba and Pseudotsuga menziesii, and at $2 \mathrm{~m}$ height for Fagus sylvatica, Acer pseudoplatanus and Quercus petraea/robur. Each point represents the average of one $1 \mathrm{~cm}$-thick tangential band; each grey curve represents one tree; the coloured solid lines show the LOESS smoothing for each species
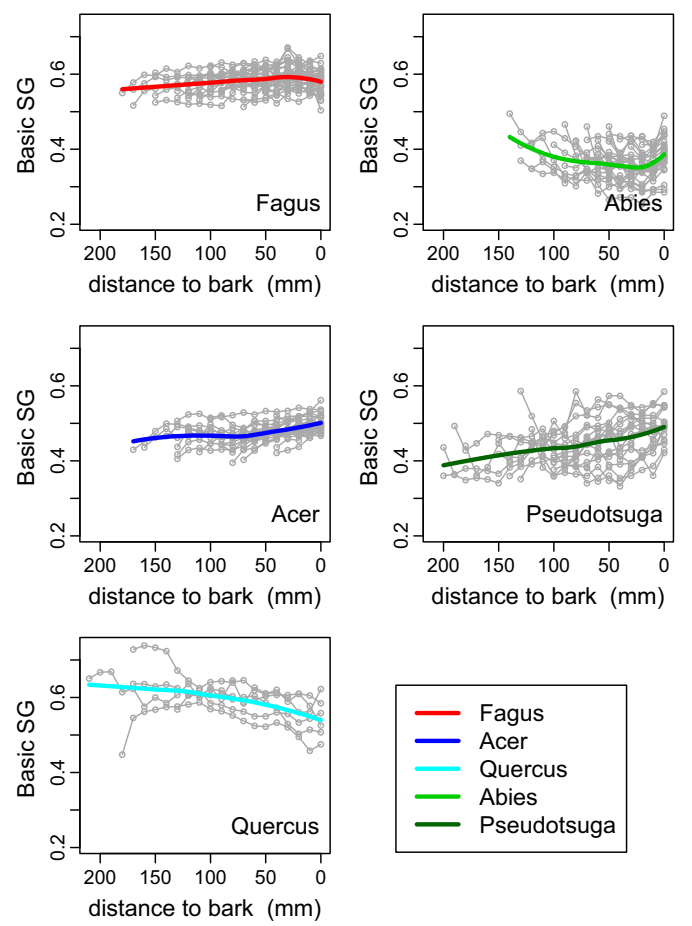

Fig. 10 Variations of basic specific gravity (BSG) with distance to bark (mm) at $1.3 \mathrm{~m}$ height for Abies alba and Pseudotsuga menziesii, and at $2 \mathrm{~m}$ height for Fagus sylvatica, Acer pseudoplatanus and Quercus petraea/robur. Each point represents the average of one $1 \mathrm{~cm}$-thick tangential band; each grey curve represents one tree; the coloured solid lines show the LOESS smoothing for each species 

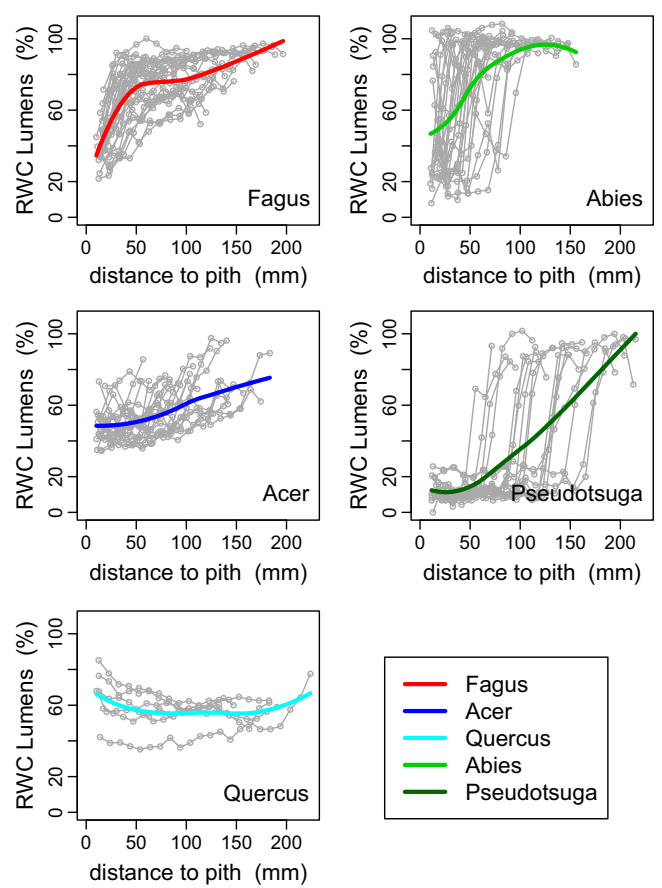

Fig. 11 Variations of relative water content of lumens (RWCL) with radius (distance to pith in $\mathrm{mm}$ ) at $1.3 \mathrm{~m}$ height for Abies alba and Pseudotsuga menziesii, and at $2 \mathrm{~m}$ height for Fagus sylvatica, Acer pseudoplatanus and Quercus petraea/robur. Each point represents the average of one $1 \mathrm{~cm}$-thick tangential band; each grey curve represents one tree; the coloured solid lines show the LOESS smoothing for each species
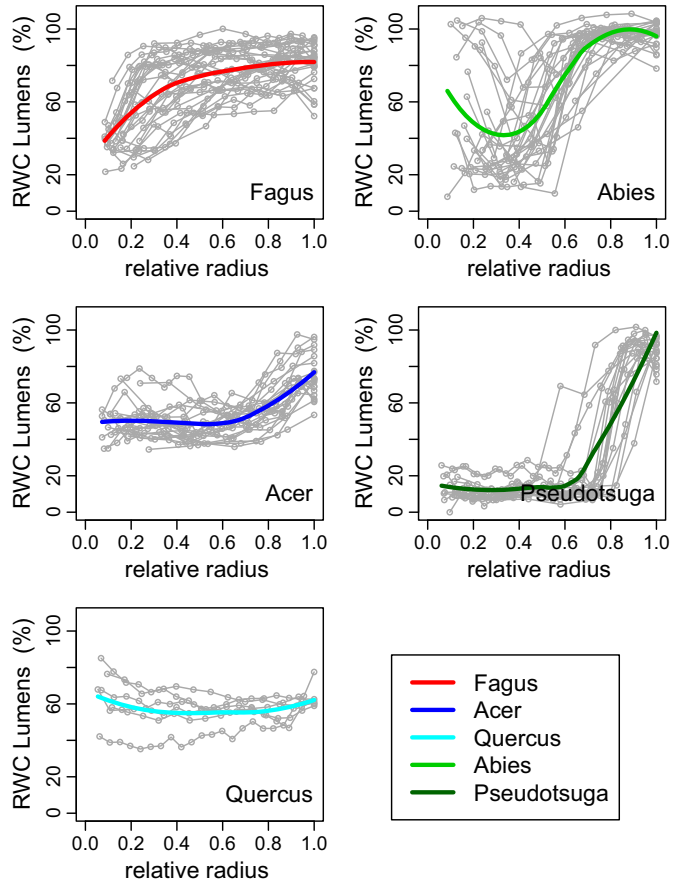

Fig. 12 Variations of relative water content of lumens (RWCL) with relative radius at $1.3 \mathrm{~m}$ height for Abies alba and Pseudotsuga menziesii, and at $2 \mathrm{~m}$ height for Fagus sylvatica, Acer pseudoplatanus and Quercus petraea/robur. Each point represents the average of one $1 \mathrm{~cm}-$ thick tangential band; each grey curve represents one tree; the coloured solid lines show the LOESS smoothing for each species
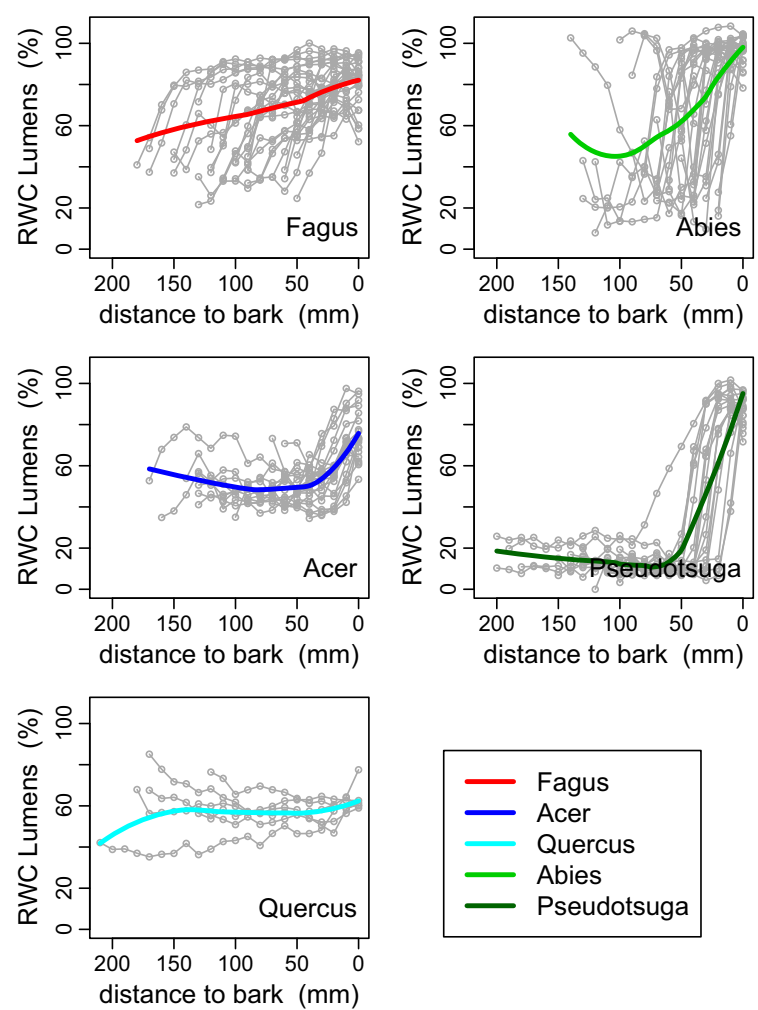

Fig. 13 Variations of relative water content of lumens (RWCL) with distance to bark (mm) at $1.3 \mathrm{~m}$ height for Abies alba and Pseudotsuga menziesii, and at $2 \mathrm{~m}$ height for Fagus sylvatica, Acer pseudoplatanus and Quercus petraea/robur. Each point represents the average of one $1 \mathrm{~cm}$-thick tangential band; each grey curve represents one tree; the coloured solid lines show the LOESS smoothing for each species

relative radius and distance to bark $(\mathrm{mm})$ at $1.3 \mathrm{~m}$ height for Abies alba and Pseudotsuga menziesii, and at $2 \mathrm{~m}$ height for Fagus sylvatica, Acer pseudoplatanus and Quercus petraea/robur. Each point represents the average of one 1 $\mathrm{cm}$-thick tangential band; each grey curve represents one tree; the coloured solid lines show the LOESS smoothing for each species.

\section{Appendix B: Vertical variations per tree and species and associated vertical trends per species}

Variations of basic specific gravity $(B S G)$ and relative water content of lumens $\left(R W C_{L}\right)$ with height $(\mathrm{m})$, relative height and distance to apex (m). Each point represents the average of one disc; each grey curve represents one tree; the coloured solid lines show the LOESS smoothing for each species. 

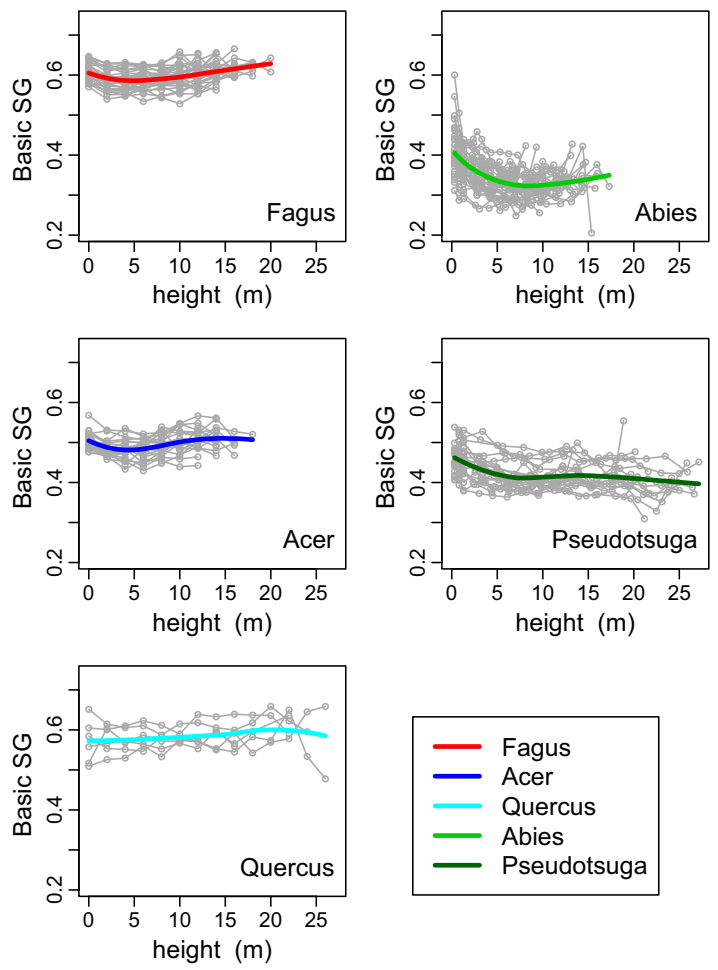

Fig. 14 Variations of basic specific gravity (BSG) with height (m). Each point represents the average of one disc; each grey curve represents one tree; the coloured solid lines show the LOESS smoothing for each species
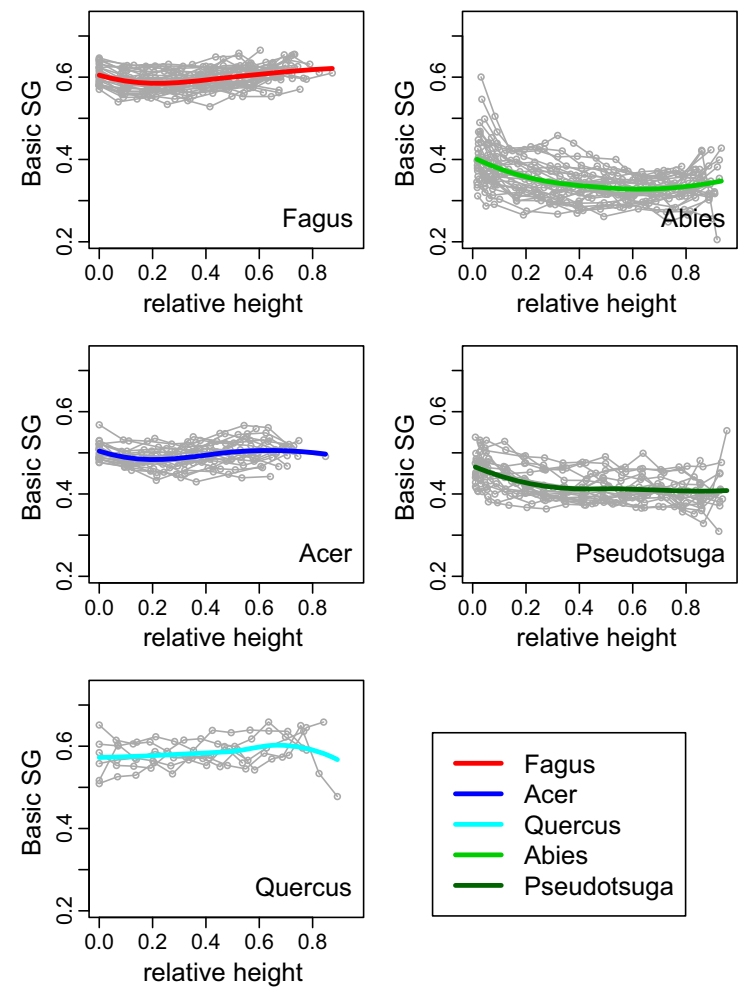

Fig. 15 Variations of basic specific gravity (BSG) with relative height. Each point represents the average of one disc; each grey curve represents one tree; the coloured solid lines show the LOESS smoothing for each species
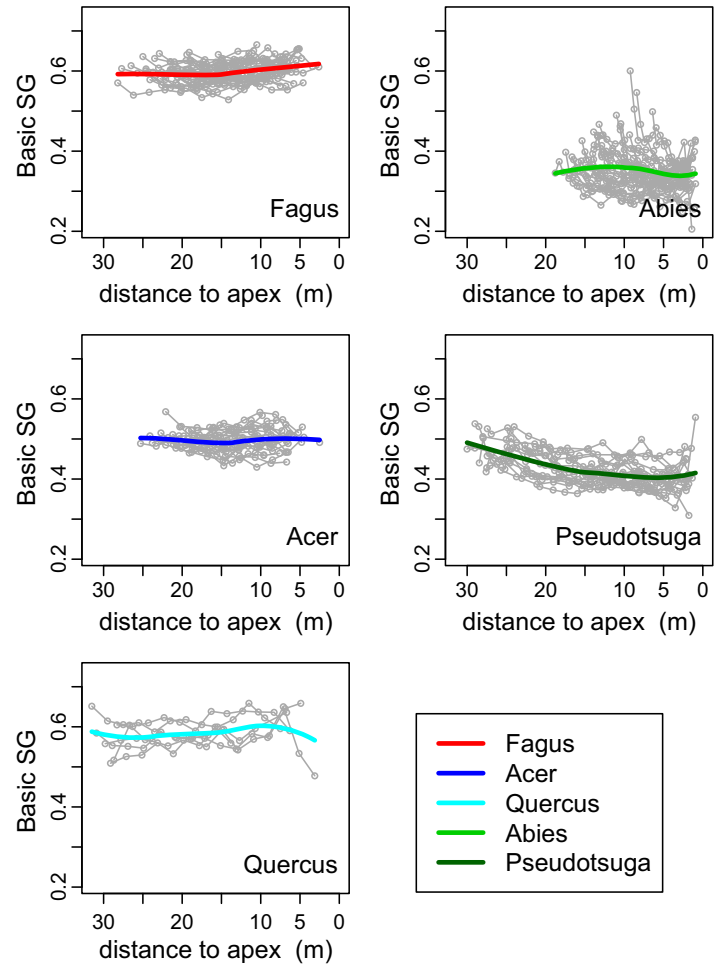

Fig. 16 Variations of basic specific gravity (BSG) with distance to apex $(\mathrm{m})$. Each point represents the average of one disc; each grey curve represents one tree; the coloured solid lines show the LOESS smoothing for each species
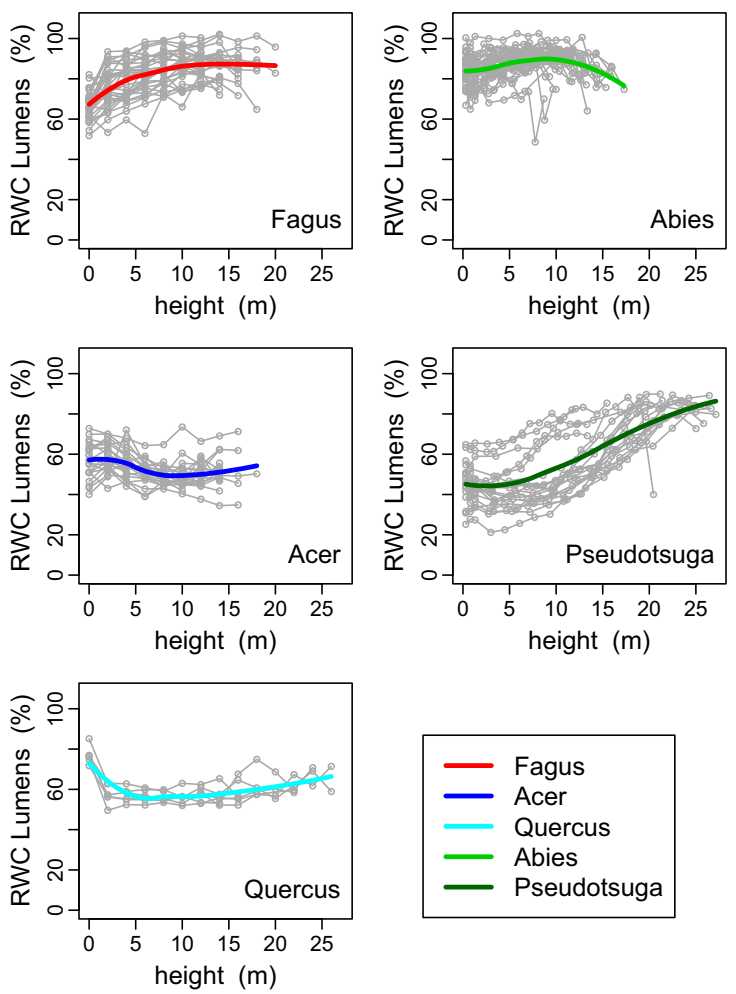

Fig. 17 Variations of relative water content of lumens (RWCL) with height $(\mathrm{m})$. Each point represents the average of one disc; each grey curve represents one tree; the coloured solid lines show the LOESS smoothing for each species 

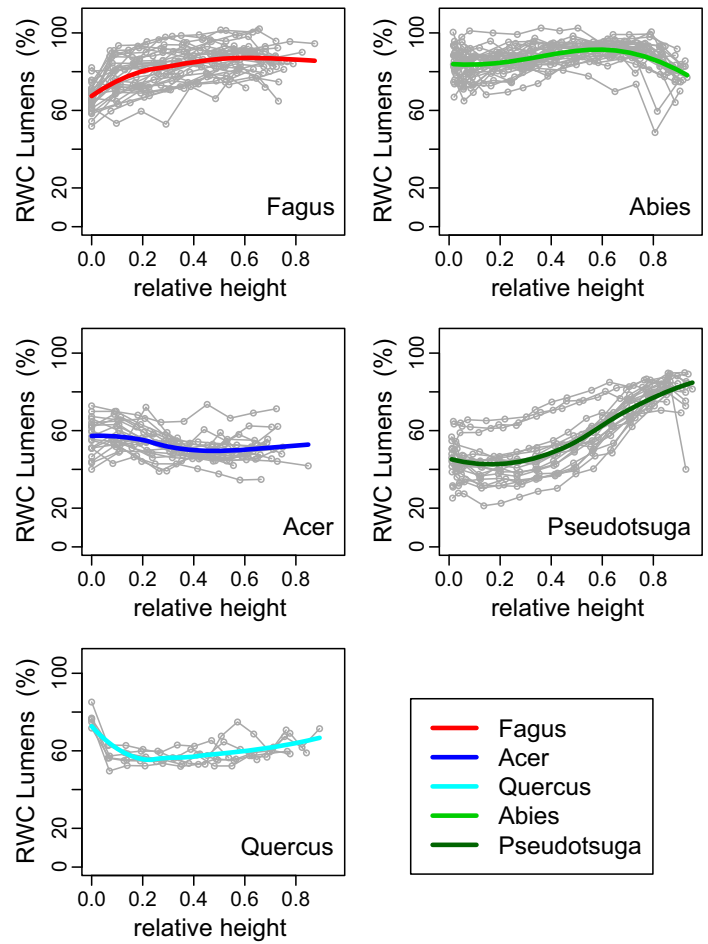

Fig. 18 Variations of relative water content of lumens (RWCL) with relative height. Each point represents the average of one disc; each grey curve represents one tree; the coloured solid lines show the LOESS smoothing for each species
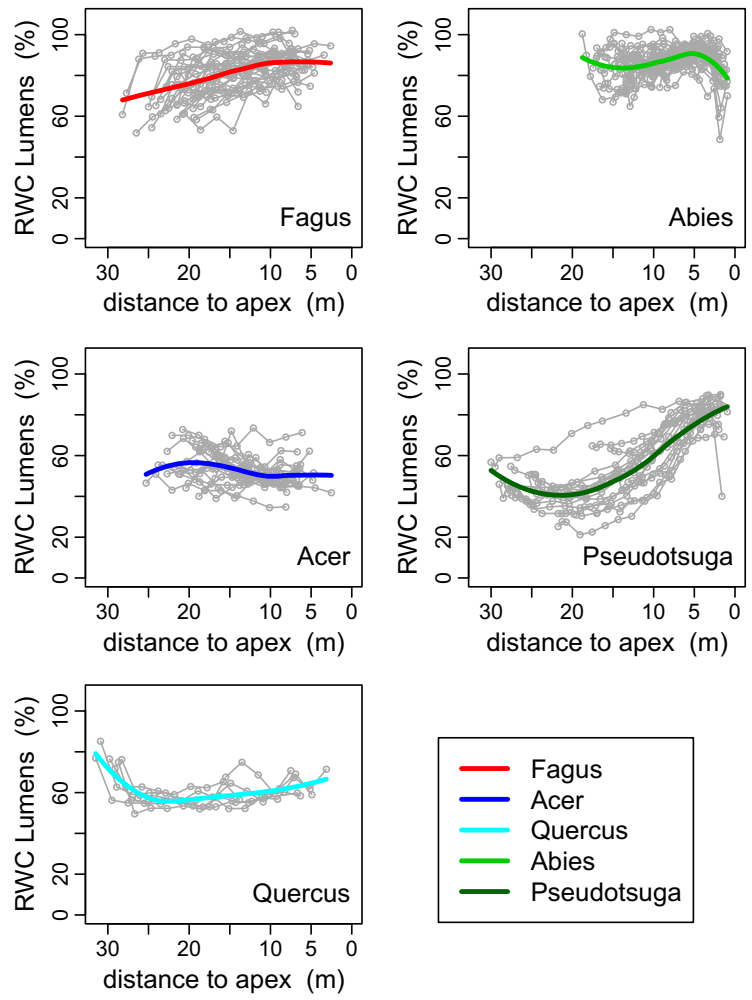

Fig. 19 Variations of relative water content of lumens (RWCL) with distance to apex (m). Each point represents the average of one disc; each grey curve represents one tree; the coloured solid lines show the LOESS smoothing for each species

\section{References}

Badel E, Ewers FW, Cochard H, Telewski FW (2015) Acclimation of mechanical and hydraulic functions in trees: impact of the thigmomorphogenetic process. Front Plant Sci 6:266

Barbaroux C, Bréda N (2002) Contrasting distribution and seasonal dynamics of carbohydrate reserves in stem wood of adult ringporous sessile oak and diffuse-porous beech trees. Tree Physiol 22:1201-1210

Bastin J-F, Fayolle A, Tarelkin Y, Van den Bulcke J, De Haulleville T, Mortier F, Beeckman H, Van Acker J, Serckx A, Bogaert J et al (2015) Wood specific gravity variations and biomass of central african tree species: the simple choice of the outer wood. PLoS One 10:e 0142146

Bauch J, Klein P, Frühwald A, Brill H (1979) Alterations of wood characteristics in abies alba mill. due to "fir-dying" and considerations concerning its origin. Eur J For Pathol 9:321-331

Beeckman H (2016) Wood anatomy and trait-based ecology. IAWA J $37: 127-151$

Bontemps J-D, Gelhaye P, Nepveu G, Hervé J-C (2013) When tree rings behave like foam: moderate historical decrease in the mean ring density of common beech paralleling a strong historical growth increase. Ann For Sci 70:329-343

Bouffier L, Gartner B, Domec J-C (2003) Wood density and hydraulic properties of ponderosa pine from the Willamette valley vs. the Cascade mountains. Wood Fiber Sci 35:217-233

Chave J, Coomes D, Jansen S, Lewis SL, Swenson NG, Zanne AE (2009) Towards a worldwide wood economics spectrum. Ecol Lett 12:351-366

Cochard H, Herbette S, Barigah T, Badel E, Ennajeh M, Vilagrosa A (2010) Does sample length influence the shape of xylem embolism vulnerability curves? A test with the cavitron spinning technique. Plant, Cell Envir 33:1543-1552

Cochard H, Tyree MT (1990) Xylem dysfunction in quercus: vessel sizes, tyloses, cavitation and seasonal changes in embolism. Tree Physiol 6:393-407

Domec J-C, Gartner BL (2002) How do water transport and water storage differ in coniferous earlywood and latewood. J Exp Bot 53:2369-2379

Filipescu CN, Lowell EC, Koppenaal R, Mitchell AK (2014) Modeling regional and climatic variation of wood density and ring width in intensively managed Douglas-fir. Can J For Res 44:220-229

Fromm JH, Sautter I, Matthies D, Kremer J, Schumacher P, Ganter C (2001) Xylem water content and wood density in spruce and oak trees detected by high-resolution computed tomography. Plant Physiol 127:416-425

Gartner BL, Moore JR, Gardiner BA (2004) Gas in stems: abundance and potential consequences for tree biomechanics. Tree Physiol 24:1239-1250

Gartner BL, North EM, Johnson G, Singleton R (2002) Effects of live crown on vertical patterns of wood density and growth in Douglasfir. Can J For Res 32:439-447

Gebauer T, Horna V, Leuschner C (2008) Variability in radial sap flux density patterns and sapwood area among seven co-occurring temperate broad-leaved tree species. Tree Physiol 28:1821-1830

Gilmore R, Pearson R (1969) Characterization of the strength of juvenile wood of loblolly pine (pinus taeda 1.) In: Technical Report. School of Forest Resources, North Carolina State University, p 35

Hacke UG (2015) Functional and ecological xylem anatomy. Springer

Hacke UG, Sperry JS, Pockman WT, Davis SD, McCulloh KA (2001) Trends in wood density and structure are linked to prevention of xylem implosion by negative pressure. Oecologia 126:457-461

Hietz P, Valencia R, Joseph Wright S (2013) Strong radial variation in wood density follows a uniform pattern in two neotropical rain forests. Funct Ecol 27:684-692 
King DA, Davies SJ, Tan S, Noor NS (2006) The role of wood density and stem support costs in the growth and mortality of tropical trees. J Ecol 94:670-680

Lachenbruch B, Moore JR, Evans R (2011) Radial variation in wood structure and function in woody plants, and hypotheses for its occurrence. In: Size-and age-related changes in tree structure and function. Springer, pp 121-164

Larjavaara M, Muller-Landau HC (2010) Rethinking the value of high wood density. Funct Ecol 24:701-705

Longuetaud F, Mothe F, Santenoise P, Dlouha J, Fournier M, Deleuze C (2016) Within-stem maps of wood density and water content for characterization of species: a case study on three hardwood and two softwood species. Ann For Sci 73:601-614

Lüttschwager D, Remus R (2007) Radial distribution of sap flux density in trunks of a mature beech stand. Ann For Sci 64:431438

McLean JP, Zhang T, Bardet S, Beauchêne J, Thibaut A, Clair B, Thibaut B (2011) The decreasing radial wood stiffness pattern of some tropical trees growing in the primary forest is reversed and increases when they are grown in a plantation. Ann For Sci 68:681-688

Megraw R (1985) Wood quality factors in loblolly pine: the influence of tree age, position in tree, and cultural practices on wood specific gravity, fiber length, and fibril angle. TAPPI $\mathrm{J}$

Meinzer F, James S, Goldstein G, Woodruff D (2003) Whole-tree water transport scales with sapwood capacitance in tropical forest canopy trees. Plant, Cell Envir 26:1147-1155

Nepveu G (1981) Prédiction juvénile de la qualité du bois de hêtre. Ann Sci For 38:425-447

Nepveu G (1994) Variabilité. Le Bois, Matériau d'Ingénierie, ARBOLOR, Nancy, pp 127-182

Niinemets Ü, Valladares F (2006) Tolerance to shade, drought, and waterlogging of temperate northern hemisphere trees and shrubs. Ecol Monogr 76:521-547

Nogueira EM, Fearnside PM, Nelson BW, Barbosa RI, Keizer EWH (2008) Estimates of forest biomass in the brazilian amazon: new allometric equations and adjustments to biomass from woodvolume inventories. For Ecol Manag 256:1853-1867

Osazuwa-Peters OL, Wright SJ, Zanne AE (2014) Radial variation in wood specific gravity of tropical tree species differing in growthmortality strategies. Am J Bot 101:803-811

Osunkoya OO, Sheng TK, Mahmud N-A, Damit N (2007) Variation in wood density, wood water content, stem growth and mortality among twenty-seven tree species in a tropical rainforest on borneo island. Aust Ecol 32:191-201
Plourde BT, Boukili VK, Chazdon RL (2015) Radial changes in wood specific gravity of tropical trees: inter-and intraspecific variation during secondary succession. Funct Ecol 29:111-120

Poorter L (2008) The relationships of wood-, gas- and water fractions of tree stems to performance and life history variation in tropical trees. Ann Bot 102:367-375

Repola J (2006) Models for vertical wood density of scots pine, Norway spruce and birch stems, and their application to determine average wood density. Silva Fenn 40:673

Scholz FG, Bucci SJ, Goldstein G, Meinzer FC, Franco AC, MirallesWilhelm F (2007) Biophysical properties and functional significance of stem water storage tissues in neotropical savanna trees. Plant, Cell Envir 30:236-248

Schüller E, Martínez-Ramos M, Hietz P (2013) Radial gradients in wood specific gravity, water and gas content in trees of a mexican tropical rain forest. Biotropica 45:280-287

Shortle W, Bauch J (1986) Wood characteristics of abies balsamea in the new england states compared to abies alba from sites in europe with decline problems. IAWA J 7:375-387

Streichan M, Schink B (1986) Microbial populations in wetwood of European white fir (Abies alba Mill). FEMS Microbiol Ecol 2:141-150

Wassenberg M, Chiu H-S, Guo W, Spiecker H (2015) Analysis of wood density profiles of tree stems: incorporating vertical variations to optimize wood sampling strategies for density and biomass estimations. Trees 29:551-561

Wiemann MC, Williamson GB (1989) Radial gradients in the specific gravity of wood in some tropical and temperate trees. For Sci 35:197-210

Wiemann MC, Williamson GB et al (2014) Wood specific gravity variation with height and its implications for biomass estimation. In: Forest Product Laboratory, Research Paper FPL-RP-677. USDA Forest Service, Madison, USA, p 9

Woodcock D, Shier A (2002) Wood specific gravity and its radial variations: the many ways to make a tree. Trees 16:437-443

Woodcock D, Shier A (2003) Does canopy position affect wood specific gravity in temperate forest trees. Ann Bot 91:529537

Zanne AE, Westoby M, Falster DS, Ackerly DD, Loarie SR, Arnold SE, Coomes DA (2010) Angiosperm wood structure: global patterns in vessel anatomy and their relation to wood density and potential conductivity. Am J Bot 97:207-215

Zobel BJ, Sprague JR (1998) Juvenile wood in forest trees. Springer Series in Wood Science, $\mathrm{p} 304$

Zobel BJ, Van Buijtenen JP et al (1989) Wood variation: its causes and control. Springer-Verlag 